\title{
Alkaline-Based Catalysts for Glycerol Polymerization Reaction: A Review
}

\author{
Negisa Ebadipour $\mathbb{D}^{\text {, }}$, Sébastien Paul ${ }^{\mathbb{D}}$, Benjamin Katryniok and Franck Dumeignil *(D) \\ Univ. Lille, CNRS, Centrale Lille, Univ. Artois, UMR 8181-UCCS-Unité de Catalyse et Chimie du Solide, \\ F-59000 Lille, France; negisa.ebadi-pour@centralelille.fr (N.E.); sebastien.paul@centralelille.fr (S.P.); \\ benjamin.katryniok@centralelille.fr (B.K.) \\ * Correspondence: franck.dumeignil@univ-lille.fr; Tel.: +33-(0)3-20-43-45-38
}

Received: 26 July 2020; Accepted: 2 September 2020; Published: 4 September 2020

\begin{abstract}
Polyglycerols (PGs) are biocompatible and highly functional polyols with a wide range of applications, such as emulsifiers, stabilizers and antimicrobial agents, in many industries including cosmetics, food, plastic and biomedical. The demand increase for biobased PGs encourages researchers to develop new catalytic systems for glycerol polymerization. This review focuses on alkaline homogeneous and heterogeneous catalysts. The performances of the alkaline catalysts are compared in terms of conversion and selectivity, and their respective advantages and disadvantages are commented. While homogeneous catalysts exhibit a high catalytic activity, they cannot be recycled and reused, whereas solid catalysts can be partially recycled. The key issue for heterogenous catalytic systems, which is unsolved thus far, is linked to their instability due to partial dissolution in the reaction medium. Further, this paper also reviews the proposed mechanisms of glycerol polymerization over alkaline-based catalysts and discusses the various operating conditions with an impact on performance. More particularly, temperature and amount of catalyst are proven to have a significant influence on glycerol conversion and on its polymerization extent.
\end{abstract}

Keywords: glycerol polymerization; polyglycerol; alkaline catalyst; mechanism

\section{Introduction}

In the last few years, in view of the environmental issues faced by humanity, the use of biofuels has been favored to try to limit the emissions of greenhouse gases and hence the global warning effect. Within that frame, biodiesel production has been promoted with, as a consequence, a significant increase in glycerol availability, as it is coproduced with biodiesel with a ratio of ca. $100 \mathrm{~kg}$ of glycerol per ton of biodiesel. Even if the development of the biodiesel industry seems to be a bit slowed down due to recent political decisions in Europe, this sector still generates worldwide a huge amount of glycerol which must be valorized to help sustain the economy of the biodiesel value chain. Of course, the higher is the value of the chemicals derived from glycerol, the better.

In that context, polyglycerols (PGs) are very interesting candidates. Indeed, these polymers have demonstrated excellent biocompatibility. They currently have found direct applications in the pharmaceutical, cosmetic and food sectors. PGs are a good basis for obtaining other molecules such as PGs esters, which represent a global market size of USD 1.91 billion in 2017 [1]. Considering the large variety of final applications (emulsifiers, stabilizers, antimicrobial agent, cosmetics, etc.), a dramatic increase in the production is envisioned with a global market of USD 5.52 billion in 2022.

While polyglycerols are currently produced from biosourced epichlorohydrin (Epicerol ${ }^{\circledR}$ ), the change in the customers' demand, more particularly in the cosmetic and food sectors, require products derived from nontoxic and preferably natural ingredients. This strongly encourages the manufacturers to produce PGs directly from glycerol. Currently, in Europe, manufacturers such as 
Solvay Chemicals, Lonza and, recently, Spiga Nord produce PGs from refined glycerol deriving from the biodiesel and oleochemicals industries [2].

Here, it should be noted that in the literature glycerol polymerization is referred to as etherification [3-5], oligomerization [6,7] and polymerization [8]. In this review, we use the general term "polymerization" to refer to all these denominations.

The aim of this paper is thus to review recent advances in the field of glycerol polymerization, with a specific focus on alkaline-catalyzed reaction, which fills the gap with previous reviews where focused on heterogeneous and homogeneous catalysts and PG2 applications [9], as well as clay-based catalysts and their roles in the shape selectivity [10] with the recent advances made in this field. This paper also provides a view on polyglycerols applications, on the reaction mechanism involved in alkaline-catalyzed PGs reaction, with a focus on the issue of leaching and on the stability of these heterogeneous catalysts, as this critical point was not addressed by the previous reviews. Finally, the influence of the reaction parameters on catalytic performances is also addressed.

\section{Polyglycerols Applications}

Generally, polyglycerols are highly water soluble, biocompatible and highly functional materials, which, as said above, make them very interesting in many applications related to cosmetics, food, polymers and plastic industries [9,11-13]. In the current market, di-, tri-, tetra-, penta-, hexa- and decaglycerols (PG10) are available as "linear" PGs $[9,11]$. However, the applications of PGs depend on their degree of polymerization, number of hydroxyl group, structure and properties such as viscosity or functionality. Hydroxyl functionality refers to the number of primary $\mathrm{OH}$ groups and secondary $\mathrm{OH}$ groups per molecule that make them reactive for further modifications.

As shown in Figure 1, polyglycerols have a large variety of possible chemical architectures: linear, branched, cyclic and hyperbranched (identified by ${ }^{13} \mathrm{C}$ NMR analysis). For instance, 12, 360 and 19,958,400 isomers could be formed for PG3, PG5 and PG10, respectively [14]; hence, the characterization of PGs is generally very complicated.

Hyperbranched PGs (HBPGs) can be sorted into two categories based on their molecular weight and, consequently, their applications: low molecular weight HBPGs (Mw $<2500 \mathrm{Da}$ ) and high $\mathrm{Mw}$ HBPGs with Mw of 24,000-700,000 Da [15,16].

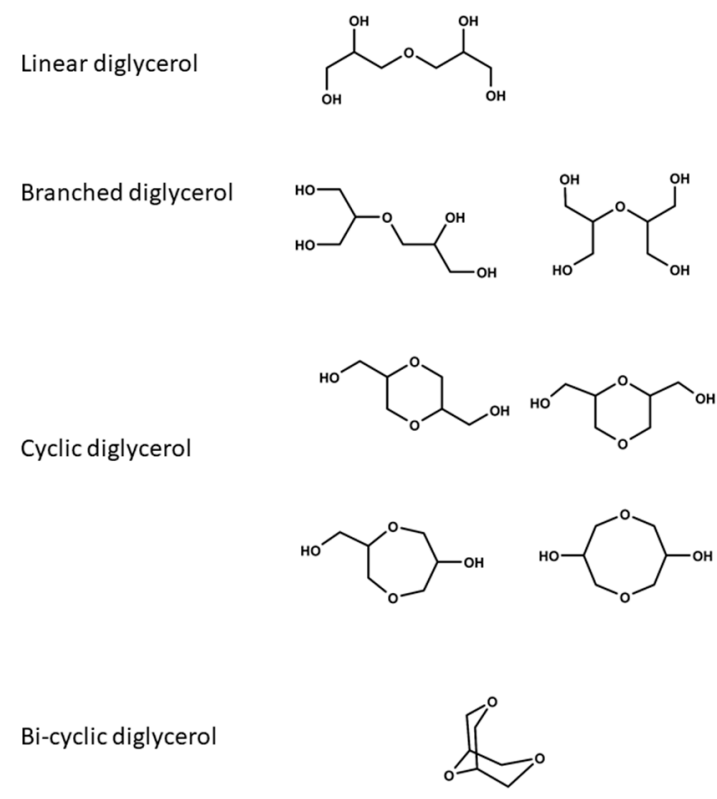

(a)

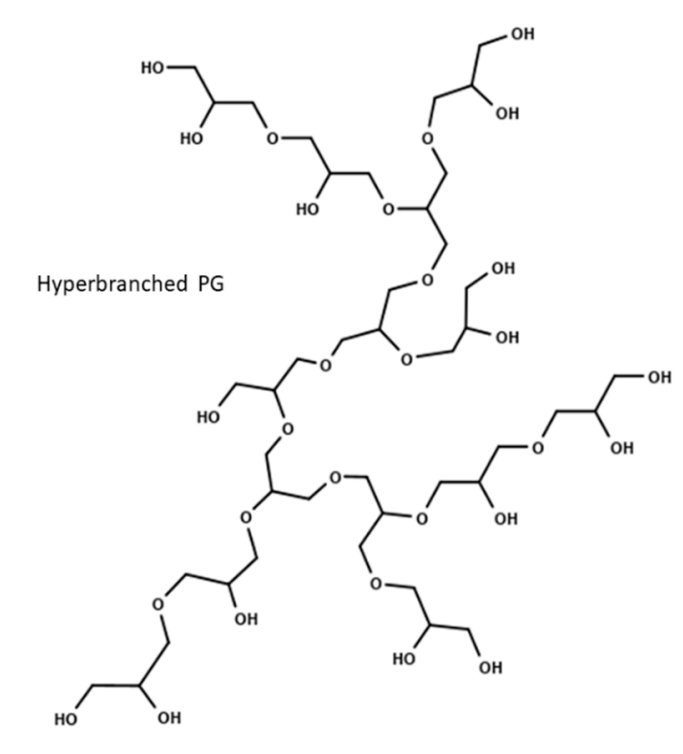

(b)

Figure 1. Different structures of: diglycerol including linear, branched and cyclic (a) (reproduced from [14]); and a hyperbranched PG (PG14) (b) (reproduced from [17]). 
Biocompatibility and functionality of polyols are function of their molecular weight and of their number of hydroxyl end-groups. For example, hyperbranched PGs with a Mw of 5000 Da could possess up to 68 hydroxyl ends-groups, which makes it a highly functional material $[18,19]$. Therefore, HBPGs could have various applications, especially in nanobiotechnology and nanomedicine depending on their molecular weight [18].

Similarly, for PGs, as shown in Table 1, by increasing the PGs molecular weight, their properties such as viscosity and numbers of hydroxyl groups (i.e., their degree of functionalization) increase.

Table 1. Properties of linear polyglycerols commonly available on the market $[11,12]$.

\begin{tabular}{|c|c|c|c|c|c|}
\hline $\begin{array}{c}\text { Name } \\
\text { (Abbreviation) }\end{array}$ & $\begin{array}{l}\text { Molecular Weight } \\
\quad\left(\mathrm{g} \mathrm{mol}^{-1}\right)\end{array}$ & $\begin{array}{c}\text { OH } \\
\text { Groups }\end{array}$ & $\begin{array}{l}\text { Viscosity } \\
\text { (CTKS }{ }^{1} \\
\left.@ 050^{\circ} \mathrm{C}\right)\end{array}$ & $\begin{array}{l}\text { Density } \\
\left(\mathrm{g} / \mathrm{cm}^{3}\right)\end{array}$ & $\begin{array}{l}\text { Hydroxyl Value } \\
\text { (mg KOH/g) }^{2}\end{array}$ \\
\hline Glycerol (G) & 92 & 3 & 45 & 1.256 & 1830 \\
\hline $\begin{array}{l}\text { Diglycerol } \\
\text { (PG2) }\end{array}$ & 166 & 4 & 287 & 1.279 & 1352 \\
\hline $\begin{array}{l}\text { Triglycerol } \\
\text { (PG3) }\end{array}$ & 240 & 5 & 647 & $\begin{array}{l}1.2646 \\
\left(40^{\circ} \mathrm{C}\right)\end{array}$ & 1169 \\
\hline $\begin{array}{l}\text { Tetraglycerol } \\
\text { (PG4) }\end{array}$ & 314 & 6 & 1067 & $\begin{array}{l}1.2687 \\
\left(40^{\circ} \mathrm{C}\right)\end{array}$ & 1071 \\
\hline $\begin{array}{c}\text { Pentaglycerol } \\
\text { (PG5) }\end{array}$ & 388 & 7 & 1408 & - & 1012 \\
\hline $\begin{array}{l}\text { Hexaglycerol } \\
\text { (PG6) }\end{array}$ & 462 & 8 & 1671 & - & 970 \\
\hline $\begin{array}{l}\text { Heptaglycerol } \\
\text { (PG7) }\end{array}$ & 536 & 9 & 2053 & - & 941 \\
\hline $\begin{array}{l}\text { Octaglycerol } \\
\text { (PG8) }\end{array}$ & 610 & 10 & 2292 & - & 920 \\
\hline $\begin{array}{c}\text { Nonaglycerol } \\
\text { (PG9) }\end{array}$ & 684 & 11 & 2817 & - & 903 \\
\hline $\begin{array}{l}\text { Decaglycerol } \\
\text { (PG10) }\end{array}$ & 758 & 12 & 3199 & - & 880 \\
\hline $\begin{array}{l}\text { Pentadecaglycerol } \\
\text { (PG15) }\end{array}$ & 1128 & 17 & 4893 & - & 846 \\
\hline
\end{tabular}

As aforementioned, due to their properties, polyglycerols have found a wide range of applications in food, cosmetics, plastics and other industries. These applications obviously depend on their structure:

Linear polyglycerols are widely used in food industry as emulsifiers upon conversion to fatty acid esters, due to their specific physical characteristics, including a clear appearance at melting point, a desirable Gardner color, a mild odor and a bland taste [12,20,21]. Approximately 500,000 metric tons of polyglycerol fatty esters are produced worldwide. Sales in the European Union and the United States are estimated at EUR 200-300 million and USD 225-275 million, respectively [22]. Note that local regulations impose certain degrees of polymerization to the food industry; for instance, according to the EU law, PGs for food applications should not contain polymers containing more than seven condensed glycerol molecules (PG7) [2]. In contrast, PG2-PG10 have the U.S. Food and Drug Administration (FDA) approval [23]. Linear polyglycerols are known as being structurally similar to polyethylene glycol (PEG), which is produced from petrol-sourced ethylene oxide. Compared to PEG, polyglycerols have a higher water-solubility and even a slightly better biocompatibility, which make them a promising and renewable alternative to PEG [24,25].

Diglycerol (PG2) is widely used in cosmetic formulations as a solvent for fragrances. This short chain PG is non-toxic and has similar properties compared to that of glycerol but with a lower volatility due to its higher molecular weight. It also has a higher refractive index than glycerol, which is suitable for clear gels. A mixture of diglycerol with menthol also enhances the evaporation and impacts flavor and longevity in products such as toothpastes and mouthwashes compared to mixtures with glycerol [2,12]. Moreover, PG2 could have application in the cosmetics industry as emulsifier upon 
conversion to polyglycerol esters to formulate oil/water emulsions for lotions, sunscreens creams and hair care products, as reported in [24] for Evonik Co. PGs with higher degree of polymerization ( $>$ PG3) are also attracting interest of cosmetics manufacturers as UV-absorbing polymers. For instance, mixture of polyglycerols containing PG3-PG12 (free of PG2 and its cyclic forms) with an average molecular weight higher than $500 \mathrm{Da}$ has been utilized to formulate sunscreens and other related products [26].

High molecular weight polyglycerols, with high degree of branching and high functionality, are of interest in the plastic industry. For instance, hyperbranched polyglycerols have already found applications as surfactants in the plastic industry for treating lithographic printing plates and as organic solvents in aqueous inkjet-printing inks to prevent paper deformation. HBPGs can also be used as performance additives in water-based printing inks due to their higher solubility in water compared to polyesters $[13,23]$.

Both linear and hyperbranched polyglycerols have the potential to be utilized in biomedical applications such as drug delivery, ophthalmic sealant for corneal wounds and anti-bacterial or anti-inflammatory agents [27]. However, polyglycerols must obviously meet drastic criteria to be used in biomedical applications such as high purity (they must be cyclic compounds-free and have a low coloration [2]).

As the physicochemical properties of polyglycerols can be varied by tuning their structure and degree of polymerization, PGs could have many other interesting applications. For instance, diglycerol can be also used as an oxygenated fuel additive [28]. PG3-PG6 have already been used as effective antifoam agents in many industries including food, pharmaceutical, cosmetic, paper, paints and coatings by partial conversion to polyglycerol esters [29,30]. PG10-PG20 can be used as foam stabilizers for oil fields and coal mines by mixing with non-ionic surfactants such as ammonia oxide [31].

\section{Industrial Routes for Polyglycerols Production}

Nowadays, polyglycerols manufacturers focus on two methods of production (Figure 2):

(a) Basic hydrolysis of epichlorohydrin and glycerol

(b) Direct polymerization of glycerol in the presence of a strong homogeneous base

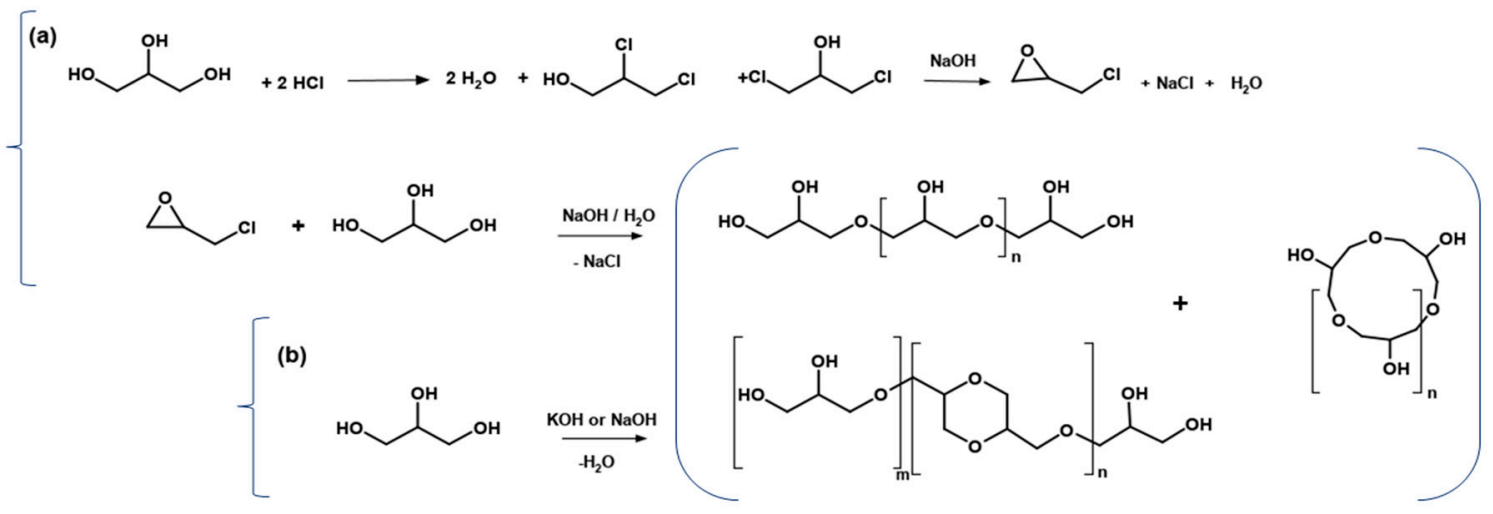

Figure 2. Industrial routes for polyglycerol production: (a) Epicerol ${ }^{\circledR}$ process, with epichlorohydrin from glycerol prior to basic hydrolysis of epichlorohydrin ( $n$ and $m=1-4)$; and (b) direct polymerization of glycerol over an alkaline homogeneous catalyst $(n$ and $m=2-10)$ (reproduced from [8,32-34]).

The first method starts from hydrolysis of epichlorohydrin to glycidol under basic conditions, before the as-formed glycidol is reacted with glycerol or unreacted epichlorohydrin to form diglycerol and higher oligomers, as shown in Figure 2a [12]. In 2011, Solvay introduced a process for the glycerol-based production of epichlorohydrin, the so-called Epicerol ${ }^{\circledR}$ process, which involves the reaction of glycerol with hydrochloric acid in the presence of Lewis acid catalysts followed by alkaline hydrolysis, as described in Figure 2a [32,33,35]. However, the overall relative low selectivity; the formation of high amounts of chloride salts (by-products); the need for many intermediate 
steps, further separation and purification steps [33,35,36]; and most importantly the highly toxic and carcinogenic raw material (epichlorohydrin) are strong disadvantages of this method [9]. In addition, due to side reactions such as dehydration and oxidation reactions undesired colored products-leading to low product quality - is also an issue [12]. Besides, from an industrial point of view, such a process requires an explosion-proof facility, which represents a high capital investment [37].

In the second route (Figure $2 \mathrm{~b}$ ), the polymerization of glycerol is carried out using a strong homogeneous basic catalyst such as $\mathrm{KOH}$ or $\mathrm{NaOH}[20,21]$. However, due to the use of the strong base, cyclic polyglycerols could form and often lead to degradation reactions forming byproducts with a dark color or a strong odor making them non-edible. Thus, bleaching agents such as hydrogen peroxide and sodium hypochlorite must be employed to improve the physical properties of the produced PGs [20], which is definitely not an environmentally-friendly solution. Using strong alkaline catalyst, such as $\mathrm{NaOH}$ and $\mathrm{KOH}$ as homogenous catalysts to directly convert glycerol to PGs, has other disadvantages: (i) the too fast reaction causes difficulty to control the degree of polymerization; (ii) the homogeneous catalyst cannot be recovered from the reaction medium and hence be reused; and (iii) strong bases induce corrosion issues of the industrial equipment.

Concerning the polymerization degree, PGs obtained by the "epichlorohydrin" route typically do not contain glycerol anymore. For instance, PG3 manufactured by Solvay contains a minimum of $80 \%$ di-, tri- and tetraglycerol, which is a mixture of linear, branched and cyclic forms, compared to a PGs manufactured by a "catalytic glycerol polymerization" route, which exhibit broader PGs' distributions [38] (Figure 3).

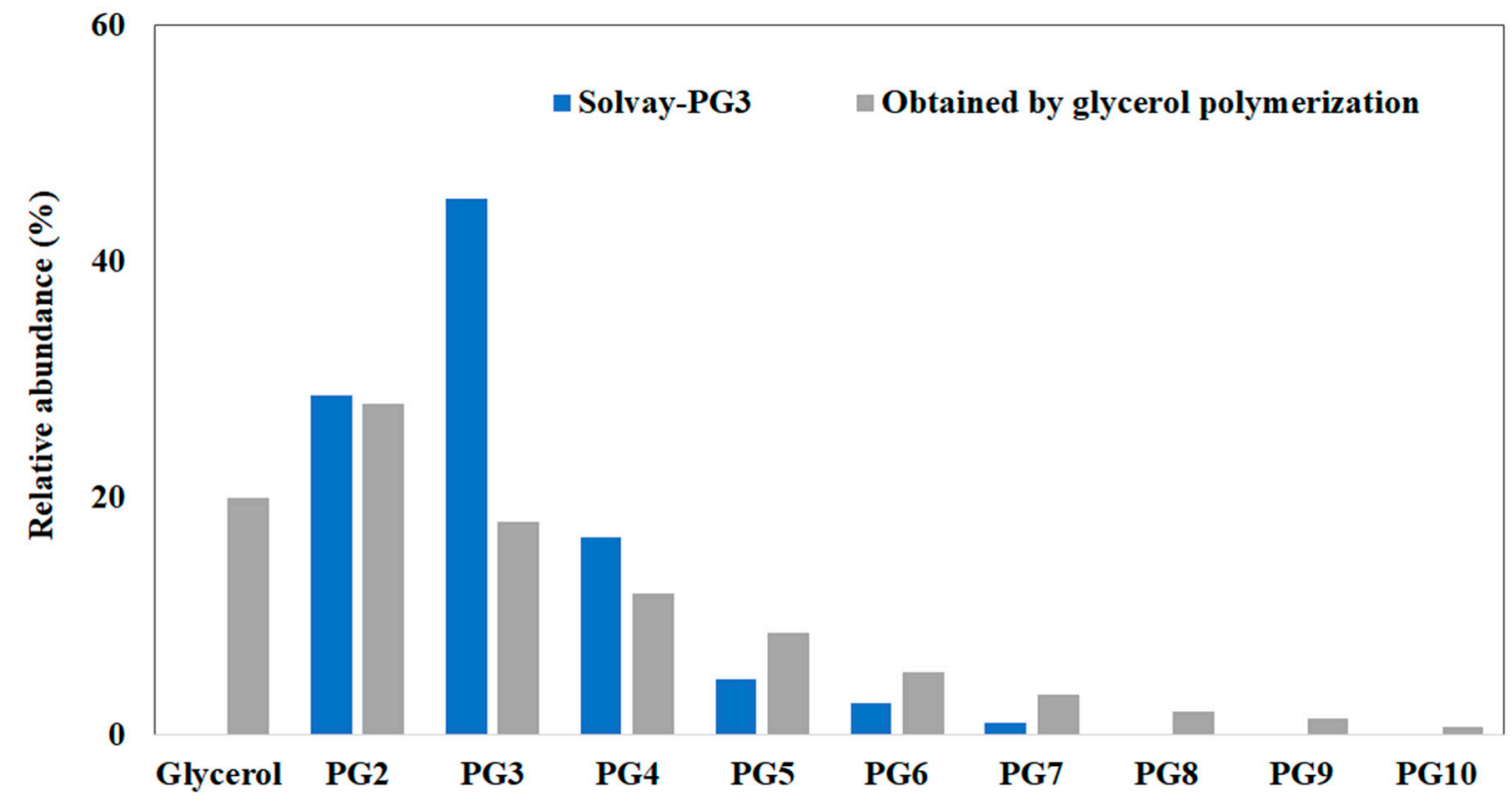

Figure 3. Comparison of polyglycerols distributions of Solvay-PG3 and polyglycerols obtained from catalytic polymerization of glycerol (average molecular weight $=250 \mathrm{Da}$ ) (reproduced from [38]).

The relative abundance in Figure 3 are described by Equation (1):

$$
\text { Relative abundance }(\%)=100 \times \frac{\text { amount of glycerol or desired PG }}{\text { total amount of glycerol and PGs }}
$$

It should be noted that the quantification of PGs is obtained by analytical methods such as gas chromatography (GC) and high-performance liquid chromatography (HPLC), which do not need prior purification. However, if purified PGs are required, this can be done by distillation of the reaction mixture, as described by Babayan and Lehman [20]. 


\section{Catalytic Systems}

Several types of catalysts have been reported in the literature to polymerize glycerol to PGs, including strong acids [39-41], alkali-modified zeolites [42,43], bulk or supported alkaline oxides [3,5, $28,44]$, alkaline carbonate and hydroxide [21,28,45,46] and impregnated basic mesoporous solids [47]. Among all these catalysts, alkaline homogeneous and heterogeneous catalysts gave better performances than acid catalysts in terms of selectivity to PGs $[9,41]$. Thus, herein, this review is focused on homogeneous and heterogenous basic catalysts.

\subsection{Homogenous Catalysis}

Historically, the first route used to produce PGs from glycerol was homogenously-catalyzed by $\mathrm{KOH}$ or $\mathrm{NaOH}$ at $200-275{ }^{\circ} \mathrm{C}$ under $\mathrm{CO}_{2}$ or $\mathrm{N}_{2}$ at atmospheric or reduced pressure. Under such conditions, and in the presence of these alkaline catalysts, a wide range of polyglycerols (PG2-PG35) was produced $[11,20,48]$.

Further, Garti et al. [46] screened the performance of several homogeneous catalysts at $260{ }^{\circ} \mathrm{C}$ under inert atmosphere. After $4 \mathrm{~h}$ of reaction in the presence of $2.5 \mathrm{~mol} \%$ catalyst, their activity, based on mole percent of formed water per glycerol, followed the order: $\mathrm{K}_{2} \mathrm{CO}_{3}(94 \%) \sim \mathrm{Li}_{2} \mathrm{CO}_{3}$ $(94 \%)>\mathrm{Na}_{2} \mathrm{CO}_{3}(92 \%)>\mathrm{KOH}(79 \%)>\mathrm{NaOH}(78 \%)>\mathrm{CH}_{3} \mathrm{ONa}(71 \%)>\mathrm{LiOH}(61 \%)$. Under these conditions, both the solubility of the catalysts in the reaction mixture and the catalyst basicity influence the reaction rate. While hydroxides are stronger bases than carbonates, $\mathrm{K}_{2} \mathrm{CO}_{3}$ was a better catalyst than $\mathrm{KOH}$ mainly due to a better solubility of the carbonate in glycerol. For the same reason, the oxides exhibited a lower activity. For instance, the rate of glycerol polymerization (based on mole percent of formed water per glycerol) was lower in the presence of $\mathrm{CaO}(7 \%)$ than $\mathrm{Ca}(\mathrm{OH})_{2}(69 \%)$, as shown in Figure 4. It should be noted that in some works, oxides and hydroxides of alkali metals were considered as homogeneous catalysts because of their partial dissolution in glycerol, while they are not totally homogenous and could thus have dual catalytic roles by actually catalyzing the reaction both homogenously and heterogeneously. This point is discussed in more detail in Section 4.3.
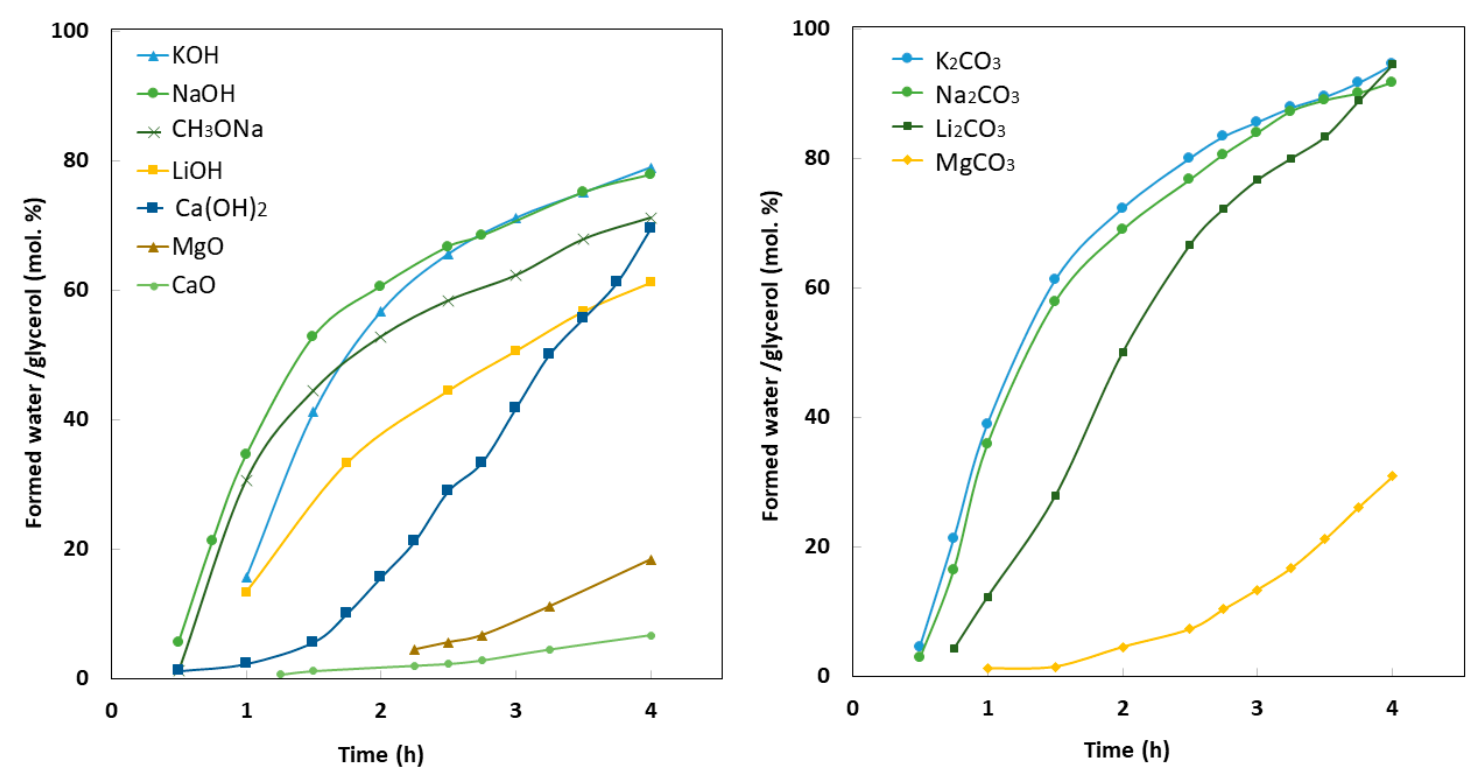

Figure 4. Rate of polymerization reactions based on mole of water formed during the reaction, using carbonates and hydroxides as catalysts (based on data presented in [46]).

However, it should be noted that the authors have not analyzed the obtained products; thus, the effect of the type of catalyst and of temperature on the polymerization degree is not clear. Similarly, Babayan and Lehman [20] used $\mathrm{KOH}$ and $\mathrm{NaOH}$ to produce mainly pentaglycerol. The reaction was carried out at $260^{\circ} \mathrm{C}$ in the presence of $2 \mathrm{wt} . \%$ of catalysts under vacuum. Although the reaction was 
stopped when the collected water reached the theoretical value of four moles, the obtained polymers were not identified and the selectivity to PGs was therefore not clearly determined. These catalysts were also applied for esterification of polyglycerols with oils to produce polyglycerols esters [20]. Charles et al. [49] also reported glycerol polymerization in the presence of $2 \mathrm{wt} . \% \mathrm{Na}_{2} \mathrm{CO}_{3}$ and $\mathrm{NaOH}$ at $240{ }^{\circ} \mathrm{C}$. After $9 \mathrm{~h}$ of reaction, glycerol conversions of $76 \%$ and $63 \%$ with selectivities of $93 \%$ and $99 \%$ to di- and triglycerol were, respectively, obtained. These results are in good agreement with those presented by Garti et al. [46], where carbonate was more active than hydroxide.

Calcium hydroxide was also used to produce linear polyglycerols by Lonza Co. [21]. The reaction was performed under vacuum at $230{ }^{\circ} \mathrm{C}$ and in the presence of only $0.1 \mathrm{wt} . \%$ of catalyst, which made it totally homogenous under such conditions. After $15 \mathrm{~h}$ of reaction, $57 \%$ of glycerol conversion was obtained with $87 \%$ of selectivity to di- and triglycerol. The maximum degree of polymerization observed was PG6. Cs salts including $\mathrm{CsHCO}_{3}, \mathrm{Cs}_{2} \mathrm{CO}_{3}$ and $\mathrm{CsOH}$ were also used for glycerol conversion to diglycerol. The reactions were carried out at a temperature of $260^{\circ} \mathrm{C}$ under atmospheric pressure with a Cs concentration of $1.85 \mathrm{mmol} \mathrm{Cs} / \mathrm{mol}$ glycerol. These catalysts release different anions in the reaction media, however, resulting in the same selectivity to diglycerol $(75 \%)$ when the glycerol conversion was 50\% [45]. Nosal et al. [50] also reported glycerol polymerization in the presence of $\mathrm{LiOH}$ as a catalyst aiming at producing only di- and triglycerols by tuning the operational conditions. After $7 \mathrm{~h}$ of reaction, glycerol conversions of $24 \%$ and $80 \%$ with selectivities of $100 \%$ and $68 \%$ to di- and triglycerol were actually obtained in the presence of $0.1 \mathrm{wt} . \% \mathrm{LiOH}$ at $230{ }^{\circ} \mathrm{C}$ and $260{ }^{\circ} \mathrm{C}$, respectively.

Table 2 summarizes the different results discussed in this section.

Table 2. Summary of the conditions and performances obtained for glycerol polymerization over homogenous catalysts.

\begin{tabular}{|c|c|c|c|c|c|c|c|}
\hline Catalyst & $\begin{array}{l}\text { Temp } \\
\left({ }^{\circ} \mathrm{C}\right)\end{array}$ & $\begin{array}{c}\text { Cat } \\
\text { (wt.\%) }\end{array}$ & $\begin{array}{l}\text { Time } \\
\text { (h) }\end{array}$ & Reaction Conditions & $\begin{array}{l}\text { Glycerol } \\
\text { Conversion } \\
(\%)\end{array}$ & $\begin{array}{l}\text { Selectivity in } \\
\text { PGx }\end{array}$ & Ref \\
\hline $\mathrm{LiOH}$ & 240 & 2 & 6 & $\begin{array}{l}\text { Continuous } \mathrm{N}_{2} \text { flow } \\
\text { using Dean-Stark system } \\
\text { to condensed water }\end{array}$ & 100 & $\mathrm{~S}_{\mathrm{PG} 2}: 20 \%$ & [51] \\
\hline $\mathrm{LiOH}$ & 230260 & 0.1 & 7 & $\begin{array}{l}\text { Low } \mathrm{N}_{2} \text { flow using } \\
\text { Dean-Stark system to } \\
\text { condensed water }\end{array}$ & $\begin{array}{l}24 \\
80\end{array}$ & $\begin{array}{l}\mathrm{S}_{\mathrm{PG} 2-3}: 100 \% \\
\mathrm{~S}_{\mathrm{PG} 2-3}: 68 \%\end{array}$ & [50] \\
\hline $\begin{array}{c}\mathrm{KOH} \\
\mathrm{NaOH}\end{array}$ & $260-280$ & $2-4$ & $1-4$ & $\begin{array}{l}\text { Continuous } \mathrm{N}_{2} \text { flow to } \\
\text { remove formed water }\end{array}$ & $90-95$ & PG10-25 & [52] \\
\hline $\begin{array}{l}\mathrm{CsHCO}_{3} \\
\mathrm{Cs}_{2} \mathrm{CO}_{3} \\
\mathrm{CsOH}\end{array}$ & 260 & $\begin{array}{l}0.4 \\
0.7 \\
0.3\end{array}$ & 8 & $\begin{array}{l}\text { Under atmospheric } \\
\text { pressure }\end{array}$ & $\begin{array}{l}64 \\
71 \\
75\end{array}$ & $\begin{array}{l}\mathrm{S}_{\mathrm{PG} 2}: 23 \% \\
\mathrm{~S}_{\mathrm{PG} 2}: 39 \% \\
\mathrm{~S}_{\mathrm{PG} 2}: 32 \%\end{array}$ & [45] \\
\hline $\mathrm{Ca}(\mathrm{OH})_{2}$ & 230 & 0.1 & - & $\begin{array}{l}\text { Under vacuum } \\
(200 \mathrm{mmHg})\end{array}$ & 57 & $\mathrm{~S}_{\mathrm{PG} 2-3}: 87 \%$ & [21] \\
\hline $\begin{array}{l}\mathrm{Na}_{2} \mathrm{CO}_{3} \\
\mathrm{NaOH}\end{array}$ & 240 & 2 & 9 & - & $\begin{array}{l}76 \\
63\end{array}$ & $\begin{array}{l}\text { SPG2-3: }_{\text {Pa }}: 93 \% \\
\text { S }_{\text {PG-3 }}: 99 \%\end{array}$ & [49] \\
\hline $\mathrm{CsOH}$ & 260 & 2 & 4 & $\begin{array}{l}\text { Under } \mathrm{N}_{2} \text { atmosphere } \\
\text { using Dean-Stark system } \\
\text { to condensed water }\end{array}$ & 90 & $\mathrm{~S}_{\mathrm{PG} 2-3}: 63 \%$ & [47] \\
\hline $\begin{array}{c}\mathrm{KOH} \\
\mathrm{NaOH}\end{array}$ & 260 & - & - & $\begin{array}{l}\text { Continuous } \mathrm{N}_{2} \text { flow to } \\
\text { remove formed water }\end{array}$ & $50-100$ & - & [20] \\
\hline
\end{tabular}

Besides the fact that, under basic homogenous catalytic reactions, the reaction rate is high, the lack of control of the glycerol polymerization degree leading to low selectivity and the impossibility to separate the catalyst from the reaction medium are still issues to be solved [12]. 


\subsection{Heterogeneous Catalysts}

In the last two decades, attention on glycerol polymerization over solid catalysts has been constantly growing, mainly because of the ease of separation by filtration or centrifugation after reaction, but also because of their higher selectivity [13].

Glycerol polymerization over basic solid catalysts has been investigated over many kinds of materials such as alkali-modified zeolites [42,43], impregnated basic mesoporous solids based on the MCM-41 family [47], bulk or supported alkaline earth metal oxides [5,6] or MgAl mixed oxides derived from layered double hydroxides [4,53]. Ruppert et al. [5] studied the catalytic effect of alkaline earth metal oxides including $\mathrm{BaO}, \mathrm{SrO}, \mathrm{CaO}$ and $\mathrm{MgO}$ with low specific surface areas $\left(<5 \mathrm{~m}^{2} \cdot \mathrm{g}^{-1}\right)$ to produce mainly di- and triglycerol, while preventing the formation of higher oligomers by performing the reactions at relatively low temperatures $\left(220^{\circ} \mathrm{C}\right)$ for $20 \mathrm{~h}$ of reaction time. The order of glycerol conversion was reported as follows: $\mathrm{BaO} \approx \mathrm{SrO}(80 \%)>\mathrm{CaO}(60 \%)>>\mathrm{MgO}(<10 \%)$. This order is in accordance with the basicity of these earth metal oxide catalysts, namely: $\mathrm{BaO}>\mathrm{SrO}>\mathrm{CaO}>\mathrm{MgO}$. In the following, the same authors tuned the surface basicity and Lewis acidity in $\mathrm{CaO}$ catalysts by using $\mathrm{CaO}$ from different sources including commercial $\mathrm{CaO}, \mathrm{Ca}(\mathrm{OH})_{2}$ and calcium nitrate, of which the physicochemical properties differ. They reported that the $\mathrm{CaO}$ sample which possesses the stronger Lewis acidity exhibited a higher glycerol conversion. However, Lewis acidity does not seem to be the sole parameter that could influence polymerization, as $\mathrm{MgO}$ which exhibits the strongest Lewis acidity among this series of catalysts has the lowest catalytic activity, whereas $\mathrm{BaO}$ and $\mathrm{SrO}$ with no Lewis acidity the highest catalytic activities.

As high selectivity towards short chains PGs, including di- and triglycerols, was of interest, research groups started to tune and design porous catalysts. In fact, the pore diameter can orientate the selectivity to particular PGs isomers through the so-called "shape selectivity" concept. For instance, to favor diglycerol selectivity, the catalyst pores should have a size larger than 0.712 and $0.753 \mathrm{~nm}$ to induce formation of $\alpha \alpha^{\prime}$ and $\beta \beta^{\prime}$ diglycerol isomers, respectively, and to enable the access of glycerol with a kinetic diameter of $0.515 \mathrm{~nm}$ (calculated by DFT) [12].

Krisnandi et al. [42] designed Na-modified microporous zeolites to enhance the shape selectivity toward diglycerol formation. The zeolite structure could induce suppression of the formation of bulky products such as trimer and higher oligomers, while diglycerol could form inside the microporous structure. Thus, $\mathrm{NaX}, \mathrm{NaY}$ and NaBeta were used as catalysts in the polymerization reaction at $260{ }^{\circ} \mathrm{C}$. For $8 \mathrm{~h}$ reaction time, $\mathrm{NaX}$ was the most active catalyst, achieving $50 \%$ glycerol conversion with $80 \%$ selectivity to diglycerol, followed by NaY and NaBeta, which led to $20 \%$ and $10 \%$ glycerol conversion, respectively, with $100 \%$ selectivity to diglycerol. However, between 4 and $6 \mathrm{~h}$ reaction time, Na started to leach out of the zeolite, and, after $24 \mathrm{~h}$, the zeolite structure was destroyed. Thus, the high conversion observed in the presence of $\mathrm{NaX}$ was explained by its low stability in the presence of water which resulted finally in a homogenous catalytic reaction. Furthermore, there are other limitations of using microporous zeolite catalysts for glycerol polymerization reactions including mass transfer limitations in internal pores which could limit the shape selectivity and also the low selectivity to PGs [10]. For instance, Ayoub et al. [54] used a lithium-exchanged zeolite $Y$ with average pore size of $3.1 \mathrm{~nm}$ at $240{ }^{\circ} \mathrm{C}$ to polymerize glycerol and obtained $99 \%$ glycerol conversion with only $72 \%$ selectivity to polyglycerols after $8 \mathrm{~h}$ of reaction. They explained an unexpected low selectivity to diglycerol (21\%) by mass transfer limitation within internal pores while higher PGs formed at the external surface of the catalyst. However, the high glycerol conversion was probably caused by the leaching of Li into the reaction media, but this was not considered in this study.

On the other hand, Gholami et al. [55,56] also investigated glycerol polymerization over a $\mathrm{Ca}_{1.6} \mathrm{La}_{0.4} \mathrm{Al}_{0.6} \mathrm{O}_{3}$ mixed oxide catalyst. They obtained a glycerol conversion of $98 \%$ with $53 \%$ diglycerol selectivity after $8 \mathrm{~h}$ of reaction at $250^{\circ} \mathrm{C}$. They concluded that larger pores (average pore size of $18 \mathrm{~nm}$ ) lead to higher diglycerol selectivity by facilitating the diffusion of glycerol molecules into the mesopores of the catalyst. However, in the same group, a glycerol conversion of $91 \%$ with $47 \%$ diglycerol selectivity was obtained in the presence of $20 \% \mathrm{Ca}_{1.6} \mathrm{La}_{0.6} / \mathrm{MCM}-41$ with a pore diameter of 
$1.4 \mathrm{~nm}$ and in the same reaction conditions [57]. Thus, the pore size of the catalysts had not such a significant effect on diglycerol selectivity. This may be due to the fact that $\mathrm{Ca}$ and $\mathrm{Li}$ could leached into the reaction media and that then the reaction is homogeneously catalyzed [57].

García-Sancho et al. [3] designed a porous solid catalyst based on $\mathrm{Mg} / \mathrm{Al}$ mixed oxides derived from hydrotalcites and tuned the shape-selectivity of glycerol polymerization. The porous structure of these compounds was expected to promote the formation of desired short chain PGs. The reactions were carried out under batch conditions at $220^{\circ} \mathrm{C}$ for $24 \mathrm{~h}$. The authors reported only the formation of di- and triglycerol, but the conversion was relatively modest: the highest conversion was $50 \%$ over MgAl-Na at near $80 \%$ selectivity toward diglycerol, while $100 \%$ selectivity was obtained over MgAl-Urea, but with only $18 \%$ glycerol conversion. They concluded that the lower is the pore diameter of the catalyst, the higher is the diglycerol selectivity. In the same group, $\mathrm{MgFe}$ mixed oxides were developed in order to introduce heterogeneous acid sites $\left(\mathrm{Fe}^{3+}\right)$ to $\mathrm{MgO}$. Polymerization of glycerol was performed over magnesium iron hydrotalcites at $220^{\circ} \mathrm{C}$ for $24 \mathrm{~h}$ in batch reaction conditions. In these conditions, high diglycerol selectivities of $90 \%$ and $100 \%$ were obtained over $\mathrm{MgFeO}_{4}$ and $\mathrm{MgFeO}$, with a glycerol conversion of $41 \%$ and $21 \%$, respectively. The authors concluded that the acidity, basicity and porosity of the catalysts contributed to their performances. Note that acrolein formation due to the presence of acid sites in these catalysts was not reported [58].

Besides, Pérez-Barrado et al. [59] also investigated the influence of acidity and basicity of different $\mathrm{MgAl}$ and CaAl layered double hydroxides (LDHs) on short chain PGs' selectivity. They observed that catalysts with higher acidity (higher number of acidic sites) showed higher conversion (75-96\%) and low selectivity to PGs ( $88 \%$ selectivity to acrolein). In contrast, catalysts with less acid sites and higher amounts of medium strength basic sites resulted in lower conversion (24\%) and higher selectivity towards di- and triglycerol (100\%).

Similar results were reported by Sangkhum et al. [60], who studied glycerol polymerization in the presence of a Ca-Mg-Al mixed catalysts derived from layered double hydroxide. They reported the highest diglycerol selectivity of $78.3 \%$ at a relatively low glycerol conversion of $40.4 \%$ when the reaction was performed at $220{ }^{\circ} \mathrm{C}$ and in presence of $3 \mathrm{wt} . \%$ catalyst for $24 \mathrm{~h}$.

More recently, Barros et al. developed new catalysts to obtain short chain PGs. Calcined dolomite, mixed carbonate of calcium and magnesium $\left(\mathrm{CaCO}_{3} \cdot \mathrm{MgCO}_{3}\right)$ and calcined eggshell were utilized to catalyze the polymerization reaction. In the presence of dolomite, the glycerol conversion was $77 \%$ with selectivities of $51 \%$ and $3 \%$ to di- and triglycerol, respectively, at $220^{\circ} \mathrm{C}$ for $24 \mathrm{~h}$ of reaction [7]. Under the same reaction conditions, and in the presence of calcined eggshell, the glycerol conversion of $85 \%$ with $40 \%$ selectivity of diglycerol were obtained [3]. Over both catalysts, increasing the reaction temperature led to an increase in conversion but at the expense of diglycerol selectivity.

In contrast to these studies where the product of interest was diglycerol, Bruijnincx's team synthesized a new catalyst based on $\mathrm{CaO}$ in order to obtained higher PGs (>PG4). They used carbon nanofibers $(\mathrm{CNF})$ as a support for $\mathrm{CaO}$ to yield larger specific surface areas while the active species $(\mathrm{CaO})$ was mostly unaffected by the presence of the $\mathrm{CNF}$ as the interactions between $\mathrm{CNF}$ as a support and active phase were low. The highest conversion was obtained in the presence of $14 \% \mathrm{CaO} / \mathrm{CNF}$ with a glycerol conversion was $76 \%$ with selectivities to di-, tri-, tetra- and higher oligomers of $38 \%$, $20 \%, 10 \%$ and $5 \%$, respectively, at $220{ }^{\circ} \mathrm{C}$ after $24 \mathrm{~h}$ of reaction $[6,44,61]$.

Table 3 summarizes the results of the studies on glycerol polymerization over heterogeneous catalysts. However, with respect to the problem of leaching and hydrothermal stability of the catalysts, one cannot clearly conclude if all the reported results on heterogeneous catalysts do not finally exhibit a contribution of homogeneous catalysis from leached or dissolved species. Hence, we discuss this issue in the next section. 
Table 3. Summary of the conditions and performances obtained for glycerol polymerization over heterogeneous catalysts.

\begin{tabular}{|c|c|c|c|c|c|c|c|}
\hline Catalyst & $\begin{array}{l}\text { Temp } \\
\left({ }^{\circ} \mathrm{C}\right)\end{array}$ & $\begin{array}{c}\text { Cat } \\
\text { (wt.\%) }\end{array}$ & $\begin{array}{l}\text { Time } \\
\text { (h) }\end{array}$ & Reaction Conditions & $\begin{array}{l}\text { Glycerol } \\
\text { Conversion } \\
(\%)\end{array}$ & $\begin{array}{l}\text { Selectivity to } \\
\text { PGx }\end{array}$ & Ref \\
\hline Ca-MgAl LDH & 220 & 3 & 24 & $\begin{array}{l}\text { Under } \mathrm{N}_{2} \text { flow using Dean-Stark system } \\
\text { to collect water }\end{array}$ & 40.4 & $\mathrm{~S}_{\mathrm{PG} 2}: 78.3 \%$ & [60] \\
\hline $\begin{array}{l}\text { Dolomite (mixed } \\
\text { oxide } \mathrm{CaO}-\mathrm{MgO})\end{array}$ & 245 & 2 & 24 & $\begin{array}{l}\text { Under } \mathrm{N}_{2} \text { atmosphere using Dean-Stark } \\
\text { system to condense water }\end{array}$ & 90 & $\begin{array}{l}\mathrm{S}_{\mathrm{PG} 2}: 23 \% \\
\mathrm{~S}_{\mathrm{PG} 3}: 22 \%\end{array}$ & [7] \\
\hline Calcined eggshell & 220245 & 2 & 24 & Under $\mathrm{N}_{2}$ atmosphere & $\begin{array}{c}85 \\
100\end{array}$ & $\begin{array}{l}\mathrm{S}_{\mathrm{PG} 2}: 35 \% \\
\mathrm{~S}_{\mathrm{PG} 3}: 15 \%\end{array}$ & [3] \\
\hline Duck bones & 240 & 2 & 12 & $\begin{array}{l}\text { Under } \mathrm{N}_{2} \text { atmosphere using Dean-Stark } \\
\text { system to condense water }\end{array}$ & 99 & - & [51] \\
\hline $14 w t . \% \mathrm{CaO} / \mathrm{CNF}$ & 220 & $0.46^{*}$ & 24 & $\begin{array}{l}\text { Under Ar gas flow using Dean-Stark } \\
\text { system to condense water }\end{array}$ & 76 & $\begin{array}{l}\mathrm{S}_{\mathrm{PG} 2}: 40 \% \\
\mathrm{~S}_{\mathrm{PG} 3}: 15 \%\end{array}$ & [44] \\
\hline $\begin{array}{l}\text { MgAl-LDHs- } \\
\text { CaAl-LDHs: } \\
\text { cHT1 }\end{array}$ & 235 & 2 & 24 & $\begin{array}{l}\text { Under } \mathrm{N}_{2} \text { atmosphere using Dean-Stark } \\
\text { system to condense water }\end{array}$ & 24 & $\mathrm{~S}_{\mathrm{PG} 2-3}: 100 \%$ & [59] \\
\hline $\begin{array}{l}\text { MgAl-LDHs- } \\
\text { CaAl-LDHs: } \\
\text { cHT2 }\end{array}$ & 235 & 2 & 24 & $\begin{array}{l}\text { Under } \mathrm{N}_{2} \text { atmosphere using Dean-Stark } \\
\text { system to condensed water }\end{array}$ & 96 & $\begin{array}{c}\mathrm{S}_{\mathrm{PG} 2-3}: 12 \% \\
\mathrm{~S}_{\text {acrolein }}: 88 \%\end{array}$ & [59] \\
\hline $\mathrm{MgFeO}_{4}$ & 220 & - & 24 & $\begin{array}{l}\text { Under } \mathrm{N}_{2} \text { atmosphere using Dean-Stark } \\
\text { system to condensed water }\end{array}$ & 41 & $\begin{array}{l}\mathrm{S}_{\mathrm{PG} 2}: 90 \% \\
\mathrm{~S}_{\mathrm{PG} 3}: 10 \%\end{array}$ & [58] \\
\hline $\mathrm{Ca}_{1 \cdot 6} \mathrm{La}_{0 \cdot 4} \mathrm{Al}_{0 \cdot 6} \mathrm{O}_{3}$ & 250 & 2 & 8 & $\begin{array}{l}\text { Under } \mathrm{N}_{2} \text { atmosphere using Dean-Stark } \\
\text { system to condensed water }\end{array}$ & 96.3 & $\mathrm{~S}_{\mathrm{PG2}-3}: 86 \%$ & [55] \\
\hline MgAl-Na & 220 & 2 & 24 & $\begin{array}{l}\text { Under } \mathrm{N}_{2} \text { atmosphere using Dean-Stark } \\
\text { system to condensed water }\end{array}$ & 50 & $\begin{array}{l}\mathrm{S}_{\mathrm{PG} 2}: 85 \% \\
\mathrm{~S}_{\mathrm{PG} 3}: 15 \%\end{array}$ & [4] \\
\hline $\begin{array}{l}\mathrm{Ca}(\mathrm{OH})_{2} \\
\mathrm{CaCO}_{3}\end{array}$ & 140 & 2.4 & $\sim 6$ & $\begin{array}{c}\text { Under reduced pressure using } \\
\text { Dean-Stark system to condensed water }\end{array}$ & $\begin{array}{l}12 \\
11 \\
\end{array}$ & - & [40] \\
\hline $\mathrm{CaO} / \mathrm{Ca}_{12} \mathrm{Al}_{14} \mathrm{O}_{33}$ & $200-250$ & - & 24 & $\begin{array}{l}\text { Under } \mathrm{N}_{2} \text { atmosphere using Dean-Stark } \\
\text { system to condensed water }\end{array}$ & - & Linear PGs & [62] \\
\hline $\begin{array}{c}\text { Zeolite NaX } \\
\text { Zeolite NaY } \\
\text { Zeolite Na Beta }\end{array}$ & 260 & 2 & 24 & Under Ar atmosphere & $\begin{array}{l}100 \\
80 \\
50\end{array}$ & $\begin{array}{l}\mathrm{S}_{\mathrm{PG} 2}: 15 \% \\
\mathrm{~S}_{\mathrm{PG} 2}: 58 \% \\
\mathrm{~S}_{\mathrm{PG} 2:}: 90 \%\end{array}$ & [42] \\
\hline $\begin{array}{l}\mathrm{MgO} \\
\mathrm{BaO}-\mathrm{SrO} \\
\mathrm{CaO}\end{array}$ & 220 & 2 & 20 & $\begin{array}{l}\text { Under Ar atmosphere using Dean-Stark } \\
\text { system to condensed water and Ice trap } \\
\text { for acrolein }\end{array}$ & $\begin{array}{c}10 \\
80 \\
>80 \\
\end{array}$ & $\mathrm{~S}_{\mathrm{PG} 2-3}: 90 \%$ & [5] \\
\hline $\mathrm{Cs}_{25} \mathrm{Al}(\mathrm{Si} / \mathrm{Al}: 20)$ & 260 & 2 & 20 & $\begin{array}{l}\text { Under } \mathrm{N}_{2} \text { atmosphere using Dean-Stark } \\
\text { system to condensed water }\end{array}$ & 80 & $\begin{array}{l}\mathrm{S}_{\mathrm{PG} 2}: 62 \% \\
\mathrm{~S}_{\mathrm{PG} 3}: 33 \%\end{array}$ & {$[47,63]$} \\
\hline $\begin{array}{l}\text { Zeolite NaA } \\
\text { Zeolite NaZ }\end{array}$ & $200-260$ & & 22 & $\begin{array}{l}\text { Under } \mathrm{N}_{2} \text { with a reflux condenser and } \\
\text { water separator }\end{array}$ & $\begin{array}{l}84.6 \\
90.5\end{array}$ & $\begin{array}{l}\mathrm{S}_{\mathrm{PG} 2-3}: 62 \% \\
\mathrm{~S}_{\mathrm{PG} 2-3}: 52 \%\end{array}$ & [43] \\
\hline
\end{tabular}

However, the possibility of acrolein production as a by-product (mainly in the presence of acid catalysts through glycerol double dehydration) and the instability of the catalysts due to the formation of water in which they are generally partially soluble are still issues to be tackled [40].

\subsection{Partial Dissolution of Heterogeneous Catalysts}

Partial dissolution of CaO-based catalysts generally occurs in the reaction medium and hence a subsequent homogeneous catalysis contribution makes the catalytic system more complex to understand. As a matter of fact, the formation of colloidal $\mathrm{Ca}(\mathrm{OH})_{2}$ and the leaching of $\mathrm{Ca}^{2+}$ in the reaction medium following Equation (2) has been often reported in glycerol polymerization [5,6,42,47].

$$
2 \mathrm{CaO}+2 \mathrm{H}_{2} \mathrm{O} \leftrightarrow \mathrm{Ca}(\mathrm{OH})_{2(1)}+\mathrm{Ca}^{2+}+2 \mathrm{OH}^{-}
$$

Ruppert et al. [5] measured total $\mathrm{Ca}(\mathrm{OH})_{2}$ and $\mathrm{Ca}^{2+}$ in the reaction medium by inductively coupled plasma (ICP) analysis. They further observed colloidal $\mathrm{Ca}(\mathrm{OH})_{2}$ particles with a size of $50-100 \mathrm{~nm}$ by cryo-transmission electron microscopy (TEM). Their results show that the Ca concentration in the reaction medium reached 3-6 wt.\% after only $2 \mathrm{~h}$ of reaction when using calcined $\mathrm{CaO}$ as catalyst. The authors concluded that the formation of colloidal $\mathrm{Ca}(\mathrm{OH})_{2}$ and leached $\mathrm{Ca}^{2+}$ could contribute to the 
polymerization reaction beside solid phase catalyst in the reaction medium. In addition, the colloidal $\mathrm{Ca}(\mathrm{OH})_{2}$ particles could not be separated from the reaction mixture and caused a non-transparent mixture (low quality product) and progressive deactivation upon recycling.

Nieuwelink [6] studied the Ca leaching as function of the temperature for $14 \mathrm{wt} . \% \mathrm{CaO} / \mathrm{CNF}$ with dynamic light scattering (DLS) and conductivity measurements at 100,150 and $220^{\circ} \mathrm{C}$. On one hand, their results indicate that at $100^{\circ} \mathrm{C}$ no colloid formation was observed, but a large amount of dissolved $\mathrm{Ca}^{2+}$ ions, with a conductivity of $1118.7 \mu \mathrm{S} / \mathrm{cm}$, into the glycerol mixture was observed which caused the saturation of glycerol. On the other hand, at higher temperatures of 150 and $220^{\circ} \mathrm{C}$, more colloid formation and less $\mathrm{Ca}^{2+}$ free species were observed. This could be linked to the fact that the polymerization reaction at higher temperatures released more water, hence promoting the formation of colloidal $\mathrm{Ca}(\mathrm{OH})_{2}$ according to Equation (1). Further, in the same group, Kirby et al. [44] reported that the active phase derived from $\mathrm{CaO} / \mathrm{CNF}$ catalyst might be the colloidal $\mathrm{Ca}(\mathrm{OH})_{2}$ particles and $\mathrm{Ca}^{2+}$.The amounts of $\mathrm{Ca}$ and $\mathrm{Mg}$ leaching from dolomite were also determined by ICP-OES during the glycerol polymerization reaction by Barros et al. [7]. According to these authors, $49 \%$ Ca and $4 \% \mathrm{Mg}$ leached into the medium at $245^{\circ} \mathrm{C}$ after $24 \mathrm{~h}$ of reaction. They noted that a homogenous contribution of $\mathrm{CaO}$ could play a role on glycerol conversion, as a significant drop in conversion was observed when dolomite was isolated and reused for the next test.

Cs leaching has also been reported during glycerol polymerization reactions in the presence of Cs-modified zeolites [47]. A lower conversion with reused-Cs ${ }_{25} \mathrm{Al}(20)$ was observed in comparison with the initial catalyst ( $60 \%$ vs. $80 \%$ ), while both catalysts had similar selectivities to di- and triglycerol. Similarly, for Na-exchanged zeolite catalysts, Na leaching out of the zeolite framework during the first $4-8 \mathrm{~h}$ of reaction followed by total dissolution of the solid catalysts at $260^{\circ} \mathrm{C}$ and after $24 \mathrm{~h}$ reaction time was also reported by [42].

Ca and Li leaching also caused a very high glycerol conversion (91\%) after $8 \mathrm{~h}$ of reaction when $20 \%$ $\mathrm{Ca}_{1.6} \mathrm{La}_{0.6} / \mathrm{MCM}-41$ was used as catalyst at $250^{\circ} \mathrm{C}$, suggesting a homogenously-catalyzed reactions [57].

To conclude, several so-called "heterogeneously-catalyzed" reactions were in fact carried out in totally or partially homogeneously-catalyzed condition, either by dissolution of the catalysts itself or by leaching of active species into the reaction medium. However, the homogeneous contributions are not very clear, as most often they were not closely studied or even considered. Most of the time the materials used are still classified as solid heterogeneous catalysts.

\section{Mechanism of Glycerol Polymerization over Alkaline Catalysts}

The mechanism of polymerization of glycerol over alkaline catalysts comprises two steps: (i) deprotonation of a hydroxyl group as a nucleophile; and (ii) attack of the as-formed alkoxy anion (glyceroxide ion) on a carbon of another glycerol molecule. However, due to the fact that hydroxyl groups are poor leaving groups, different mechanisms have been proposed to explain the process. For instance, for solid alkaline catalyst such as $\mathrm{CaO}, \mathrm{MgO}, \mathrm{BaO}$ and $\mathrm{SrO}$ [5], it is presumed that a high reaction temperature is required for the formation of PGs by facilitating the leaving of hydroxy group; another assumption is that Lewis acid sites take part in the mechanism through activation of a hydroxyl group as a leaving group (Figure 5). However, as aforementioned, the contribution of Lewis acidity in PGs reaction mechanism cannot explain the lowest activity of $\mathrm{MgO}$ and the highest activity of $\mathrm{BaO}$ and $\mathrm{SrO}$. Moreover, for other catalysts that possess Lewis acid sites such as $\mathrm{CaAl}$ layered double hydroxides, the reaction favored acrolein formation (Table 3). 


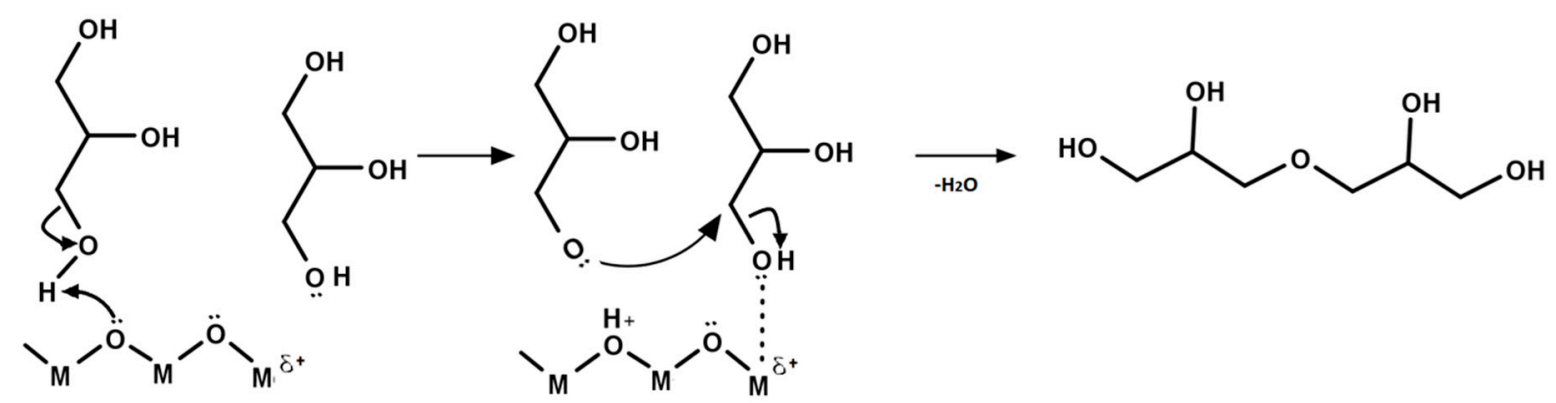

Figure 5. Reaction mechanism for glycerol polymerization over earth metal oxides catalysts as proposed by [5].

Salehpour and Dubé [40] proposed a mechanism for catalysis over $\mathrm{Ca}(\mathrm{OH})_{2}$ suggesting that a protonated glycerol is a better nucleophile that could then attack a second molecule of glycerol, as a weak electrophile, on one of the primary or secondary alcohol groups (Figure 6). This mechanism could explain the slower rate of alkaline-catalyzed reaction compared to the acid-catalyzed one, where glycerol becomes a better electrophile due to ${ }^{+} \mathrm{H}_{2} \mathrm{O}-\mathrm{C}$ bond. Thus, to break the $\mathrm{C}-\mathrm{O}$ bond and achieve a higher reaction rate, a higher reaction temperature should be applied for alkaline-catalyzed reaction. In this mechanism, calcium ions are also involved by coordinating to the oxygen atoms of glycerol. This coordination, as the so-called "pseudo-bond", could cause the carbon-oxygen bond of a glycerol molecule to lengthen and thus induce lowering of the energy of the transition state complex. In this mechanism, the $\mathrm{Ca}(\mathrm{OH})_{2}$ should be in homogeneous state to access $\mathrm{Ca}$ ions to be involved in the mechanism. Besides, this mechanism could also be assumed for $\mathrm{CaO}$, by $\mathrm{Ca}$ leaching into the reaction medium, as aforementioned. Thus, this suggests that the actual mechanism with calcium oxide and hydroxide is actually homogeneous.

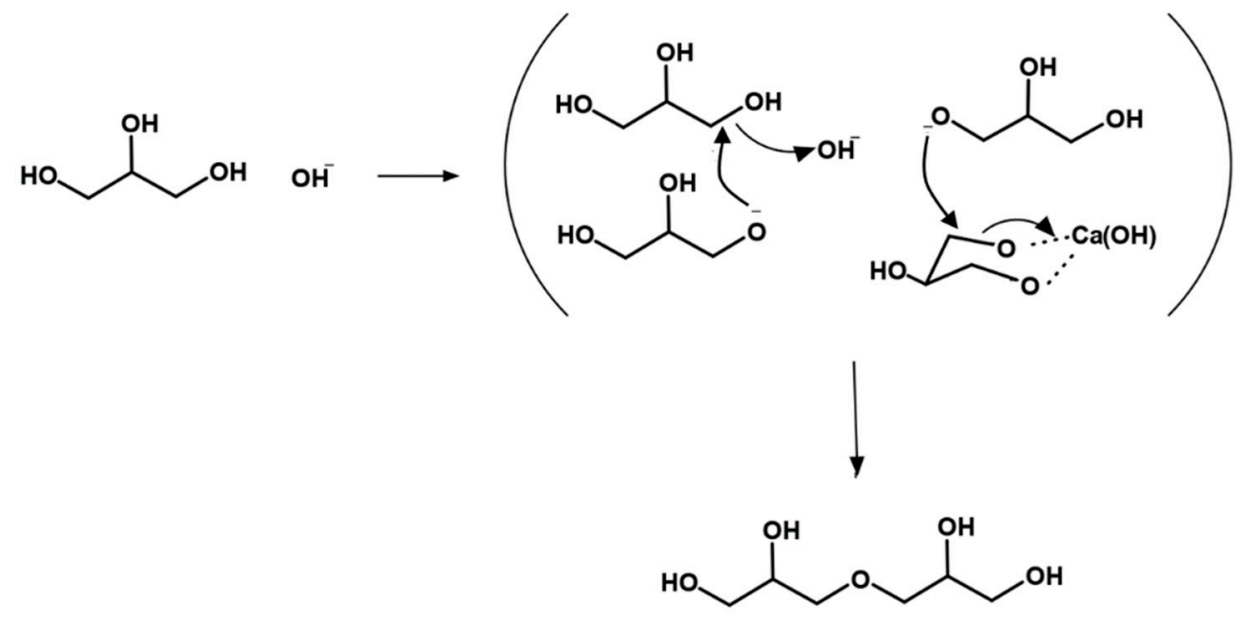

Figure 6. Reaction mechanism for glycerol polymerization with $\mathrm{Ca}(\mathrm{OH})_{2}$ as a catalyst, with contribution of $\mathrm{Ca}$ in the mechanism, as proposed in [40].

Martin and Richter [12] suggested that a homogenously alkaline-catalyzed reaction follow a SN2 mechanism, as shown in Figure 7. Similarly, the protonated glycerol molecule (glyceroxide ion) is a nucleophilic species that attacks the hydroxyl group of glycerol, and then forms a water molecule. However, the corresponding cations does not contribute to this mechanism. 


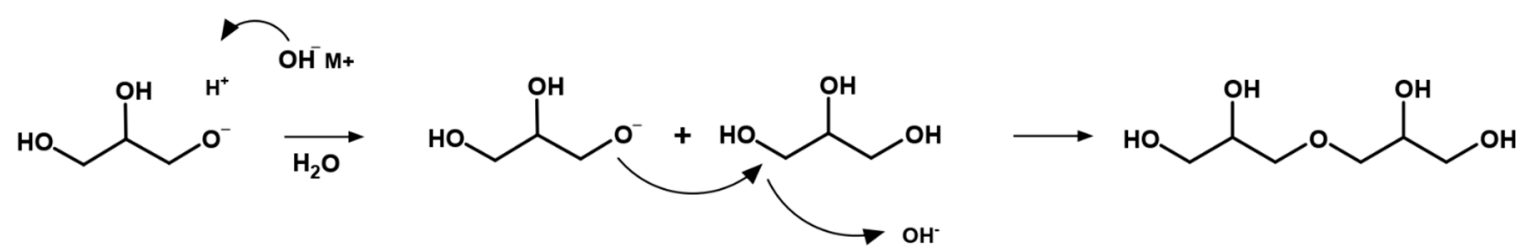

Figure 7. Reaction mechanism for homogenously catalyzed glycerol polymerization reaction, as proposed in [12].

On the other hand, Ionescu and Petrović [8] presumed that glyceroxide ion could transform to glycidol by intramolecular nucleophilic substitution. Then, glycidol, as an intermediate, reacts with the hydroxyl groups of glycerol to form a dimer (Figure 8). This is similar to the classical mechanism for formation of polyglycerols by ring opening of glycidol with a fast reaction rate at room temperature (Figure 1a) [12,64]. However, while it proposes the well-known glycidol ring opening mechanism to produce PGs, it cannot explain the roles of oxides as heterogeneous alkaline catalysts and their slower reaction rate.
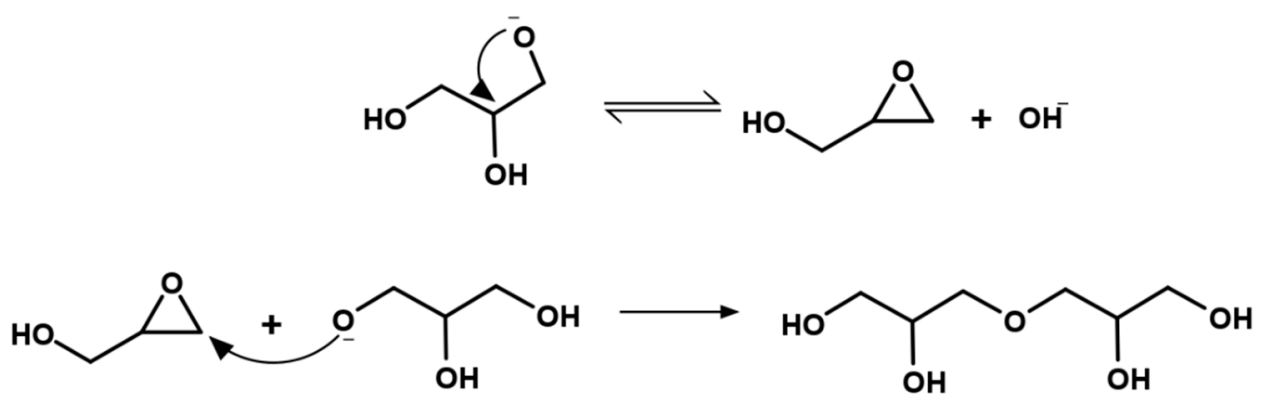

Figure 8. Reaction mechanism for alkaline-catalyzed reactions by glycidol formation, as proposed in [8].

According to all these mechanisms, glycerol polymerization reaction is subjected to a high activation energy, translated with the need of high temperatures to make the reaction possible. The operating conditions actually used are discussed in the next section.

\section{Reaction Conditions}

\subsection{Temperature}

According to the literature, temperature plays an important role in glycerol polymerization reactions catalyzed by both homogenous and heterogeneous catalysts. The studied temperature range for alkaline heterogeneously catalyzed reactions starts from $200^{\circ} \mathrm{C}$ to a maximum of $270{ }^{\circ} \mathrm{C}$, as presented in Table 3, keeping in mind that the boiling point of pure glycerol is $290{ }^{\circ} \mathrm{C}$ under atmospheric pressure [65].

Sangkhum et al. [60] studied the effect of the temperature in the polymerization of glycerol over $\mathrm{Ca}-\mathrm{MgAl}$ mixed metal oxide as a catalyst. They performed the reactions at the temperatures of 200, 210,220 and $230{ }^{\circ} \mathrm{C}$ and observed, as expected, a significant increase in glycerol conversion from $40 \%$ at $220{ }^{\circ} \mathrm{C}$ to $86 \%$ at $230{ }^{\circ} \mathrm{C}$, while glycerol conversion was only $5 \%$ and $11 \%$ at the lower temperatures of 200 and $210{ }^{\circ} \mathrm{C}$, respectively. They also reported a decrease in diglycerol selectivity from nearly $78 \%$ to $33 \%$ at 220 and $230{ }^{\circ} \mathrm{C}$, respectively.

Gholami et al. [55] investigated the effect of temperature in the presence of $\mathrm{Ca}_{1.6} \mathrm{La}_{0.4} \mathrm{Al}_{0.6} \mathrm{O}_{3}$ as a catalyst. A significant increase in glycerol conversion from $28.1 \%$ at $220{ }^{\circ} \mathrm{C}$ to nearly $96 \%$ at $260{ }^{\circ} \mathrm{C}$ after $8 \mathrm{~h}$ of reaction was reported, where the yield in di- and triglycerol was $11 \%$ and $88 \%$, respectively. However, a drop in diglycerol yield $(77 \%)$ was observed at higher temperature $\left(260^{\circ} \mathrm{C}\right)$, which was explained by the formation of higher polyglycerols (>PG3) or cyclics PGs. 
Kirby et al. [44] also studied the effect of temperature on the polymerization of glycerol and the coloration of products in the presence of CaO-CNF. They performed tests at the temperatures of 180 , 200, 220, 240 and $260^{\circ} \mathrm{C}$ and observed glycerol conversions of $\sim 10, \sim 35, \sim 55,80$ and $100 \%$, respectively. Moreover, they concluded that the highest studied temperature $\left(260^{\circ} \mathrm{C}\right)$ gave rise to the formation of undesired products (dark color products) like cyclic dimers, acrolein and other dehydration products with a decrease in selectivity to shorter PGs (PG2 and PG3).

Similar results were reported by Barros' team, that observed an increase in glycerol conversion when increasing the temperature from 200 to $245^{\circ} \mathrm{C}$ in the presence of an eggshell commercial CaO [3] and calcined dolomite [7]. For instance, the conversion increased from $10 \%$ at $200{ }^{\circ} \mathrm{C}$ to $80 \%$ and $100 \%$ at $220^{\circ} \mathrm{C}$ and $245^{\circ} \mathrm{C}$, respectively. When diglycerol selectivity decreased, the formation of acrolein increased, and a darker and more viscous product was observed, as shown in Figure 9.
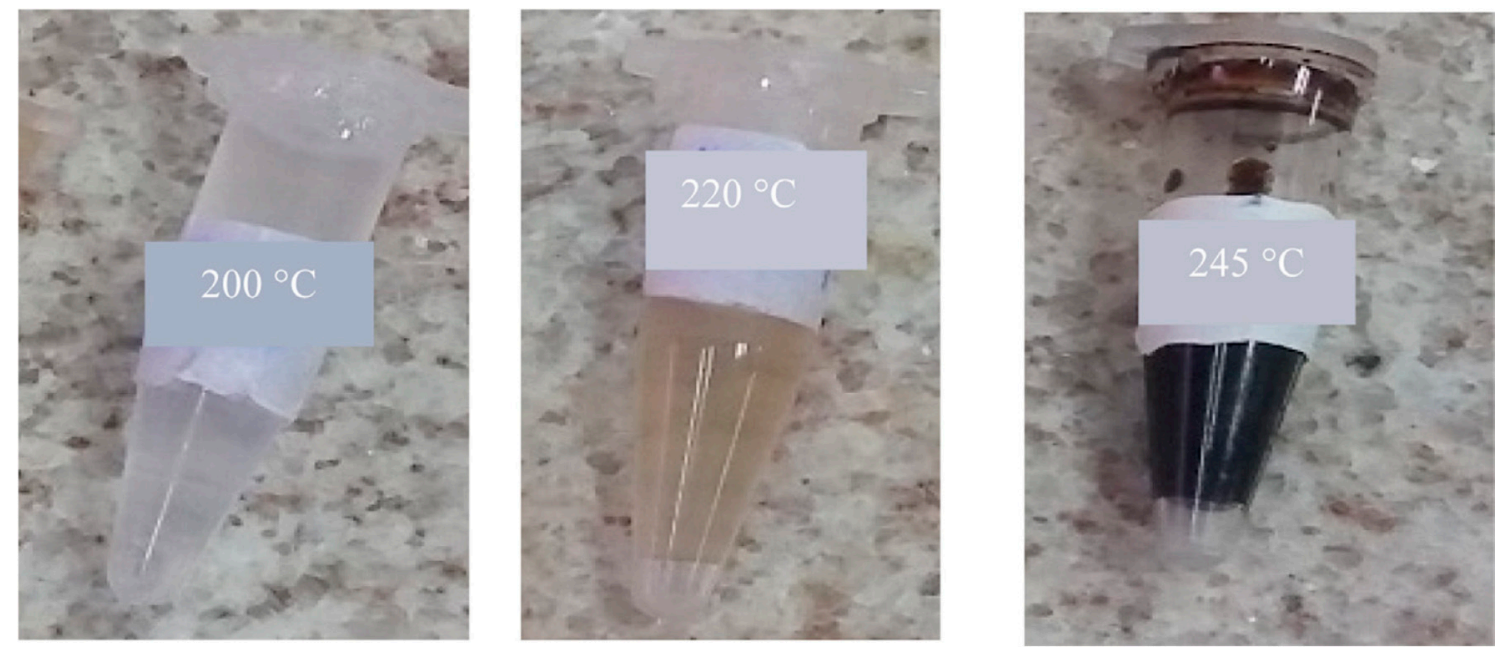

Figure 9. Effect of temperature on the transparency of the product of glycerol polymerization in the presence of calcined eggshell (CaO) (reprinted from [3], copyright 2020, Elsevier).

\subsection{Effect of Catalyst Loading}

Garti et al. [46] mentioned that increasing the amount of catalyst can accelerate the reaction rate, further affecting the overall degree of polymerization. Based on the amount of water formed during the reaction, $0.5-1 \mathrm{~mol} . \%$ of $\mathrm{NaOH}$ as a catalyst were proposed for obtaining di- and triglycerols and 4-10 mol.\% for higher degree of glycerol polymerization.

Sangkhum et al. [60] investigated the effect of $\mathrm{Ca}-\mathrm{MgAl}$ mixed oxide amount on glycerol polymerization at $220{ }^{\circ} \mathrm{C}$. According to their results, glycerol conversion increased to $20 \%$ and $40 \%$ in the presence of 2 and $3 \mathrm{wt} . \%$ of catalyst, respectively, whereas the glycerol conversion was $6 \%$ without catalyst. They reported that increasing the catalyst loading also promoted diglycerol selectivity from $40.4 \%$ to $78.3 \%$, respectively (Figure 10 ). However, when the catalyst loading was further increased at $5 \mathrm{wt} . \%$, the glycerol conversion and diglycerol selectivity declined, reaching $27.9 \%$ and $42.6 \%$, respectively. They explained this phenomenon by the increase in glycerol conversion and in the quantity of formed water in the presence of higher amount of catalyst, which might cause back-scission of polyglycerol to glycerol via hydrolysis. However, this explanation is not very convincing since the role of water in an equilibrium reaction would be the same whatever the catalytic system and catalyst amount. 


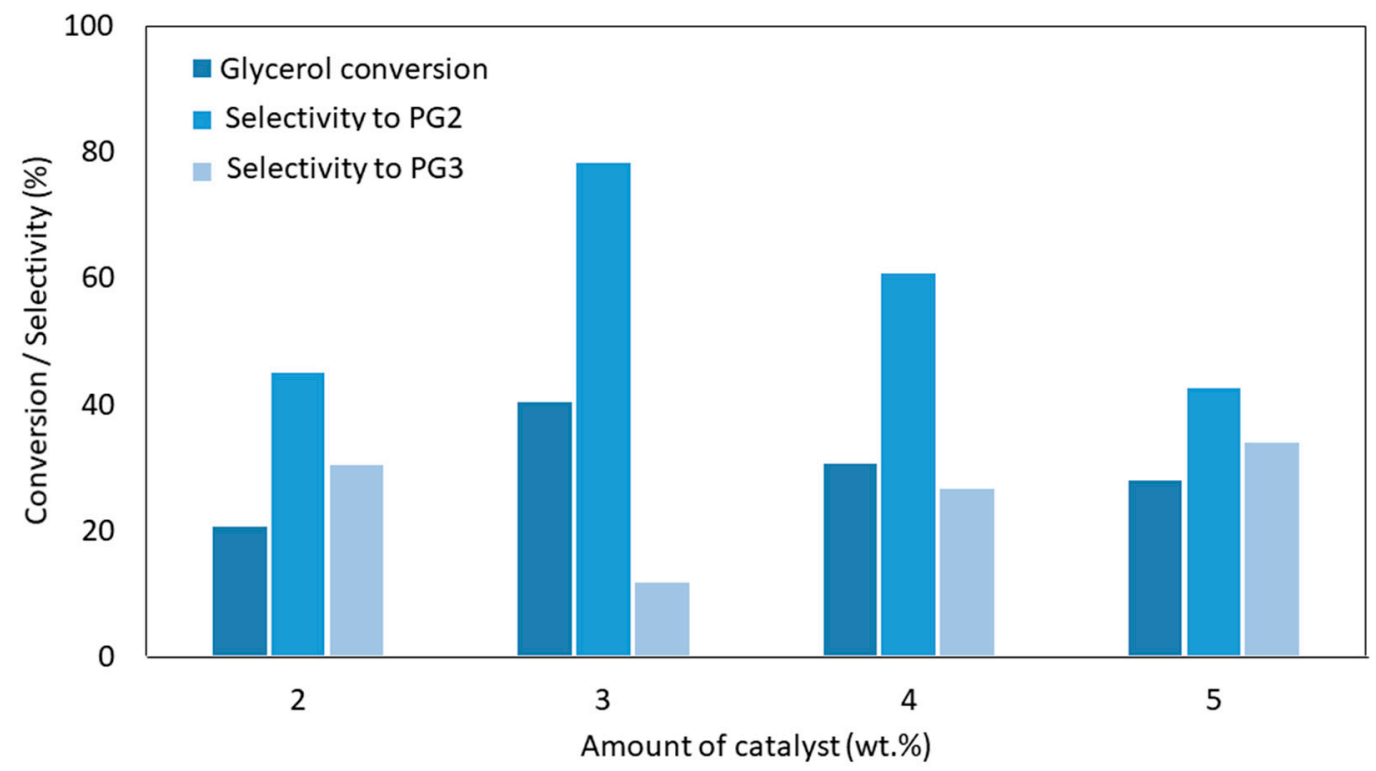

Figure 10. Catalytic conversion of glycerol over $7.5 \% \mathrm{Ca}-\mathrm{MgAl}$ mixed metal oxide at $220{ }^{\circ} \mathrm{C}$ for $24 \mathrm{~h}$ (reproduced from [60]).

Kirby et al. [44] studied the effect of $\mathrm{CaO}, \mathrm{Ca}(\mathrm{OH})_{2}$ and $\mathrm{CaO} / \mathrm{CNF}$ loading on glycerol conversion to PGs. According to their results, increasing the amount of $\mathrm{CaO}$ from 0.33 to $3.28 \mathrm{~mol} \%$ (equivalent to $2 \mathrm{wt} . \% \mathrm{CaO}$ ) had no significant effect on glycerol conversion, while for $\mathrm{CaO} / \mathrm{CNF}$, an increase in the amount of catalyst from 0.16 to 0.46 mol.\% induced an increase in conversion from $48 \%$ to $76 \%$. They explained this result by homogenous contribution of $\mathrm{CaO}$ and $\mathrm{Ca}(\mathrm{OH})_{2}$ in the reaction with complete dissolution of $\mathrm{CaO}$ in the reaction mixture at loadings up to $0.46 \mathrm{~mol} \%$ to form $\mathrm{Ca}(\mathrm{OH})_{2}$ (from $\mathrm{CaO}$ ) and $\mathrm{Ca}^{2+}$ species, as previously discussed.

On the other hand, Barros et al. [3] reported an increase in the glycerol conversion from $34 \%$ to $85 \%$ by increasing the amount of calcined eggshell $\mathrm{CaO}$ as a catalyst from 0.5 to $2 \mathrm{wt}$. $\%$ while selectivity to di- and triglycerol decrease from nearly $55 \%$ to $43 \%$.

\subsection{Pressure}

With respect to glycerol polymerization, Jungermann et al. [11] noted that using vacuum at high reaction temperature increased the glycerol conversion by eliminating the formed water from the reaction medium and lead to a narrowing of the range of PGs molecular weight. Although they did not mention any values for the applied vacuum and temperature in polymerization reaction, Lemke [16] reported the use of $230{ }^{\circ} \mathrm{C}$ and under vacuum of $200 \mathrm{~mm} \mathrm{Hg}$. However, the obtained results were not compared with results obtained at atmospheric conditions. In practice, in the case of solid catalysts, the polymerization reaction is mainly carried out under atmospheric pressure using a Dean-Stark apparatus with a reflux condenser to continuously remove water formed during the reaction (as mentioned in Table 3).

\subsection{Atmosphere}

Traces of oxygen lead to the formation of oxidation products. Therefore, to prevent parasite oxidation reactions, glycerol polymerization is preferentially carried out under an inert gas such as $\mathrm{N}_{2}$ or Ar [46]. However, while recent studies have mostly been carried out under $\mathrm{N}_{2}$ atmosphere (see Tables 2 and 3), a few studies were also carried out under $\mathrm{CO}_{2}$ atmosphere. For instance, Garti et al. [46] used both $\mathrm{N}_{2}$ and $\mathrm{CO}_{2}$ atmospheres for glycerol polymerization and reported similar production of tetra- and penta-polyglycerol under both conditions. Wilson et al. [66] employed $\mathrm{CO}_{2}$ as an inert gas to prevent oxidation for glycerol conversion to polyglycerol at $200^{\circ} \mathrm{C}$ in the presence of potassium hydroxide. However, the reason behind applying $\mathrm{CO}_{2}$ is not clear. We can suppose that 
it might be linked to the $\mathrm{CO}_{2}$ Lewis acidic nature, which could contribute to the reaction. However, the impact of $\mathrm{CO}_{2}$ highly depends on temperature, solubility of $\mathrm{CO}_{2}$ in glycerol, concentration of $\mathrm{CO}_{2}$, pressure [67] and further formation of glycerol carbonate [68]. Moreover, many studies kept $\mathrm{CaO}$ under nitrogen or used freshly calcined $\mathrm{CaO}$ in order to prevent "deactivation" of catalyst by contact with ambient air (reactions with $\mathrm{CO}_{2}$ and $\mathrm{H}_{2} \mathrm{O}$ ) and formation of $\mathrm{CaCO}_{3}$ and $\mathrm{Ca}(\mathrm{OH})_{2}$, respectively $[5,6]$.

\subsection{Reaction Time}

Polymerization of glycerol in the absence of a solvent and in the presence of a heterogeneous catalyst is a slow reaction because the reactants must diffuse into the catalyst in a viscous reaction mixture [55]. Consequently, longer reaction times are needed to overcome diffusion resistance and reach higher degrees of polymerization. For instance, Kirby et al. [44] studied the composition of reaction mixture during $24 \mathrm{~h}$ at $220^{\circ} \mathrm{C}$ in the presence of $\mathrm{CaO} / \mathrm{CNF}$. They observed an increase in formation of di- and triglycerol during the first $8 \mathrm{~h}$ of reaction, and then a progressive decrease of these compounds to the benefit of higher oligomers. Glycerol polymerization reactions catalyzed by solids generally take place within $24 \mathrm{~h}$, as shown in Table 3.

Overall, glycerol self-condensation reactions are influenced by many factors and various possible mechanisms depending on the catalyst types, etc. As a consequence, the average degree of polymerization could be affected directly by several factors including conversion. Hence, in this case, using an equation such as Carothers equation would unfortunately not describe the real average polymerization degree, and assessment of the performances by finely analyzing and comparing each output parameter is needed.

\section{Conclusions}

In this review paper, polyglycerols are shown to be very interesting polyols with a wide range of structures and, accordingly, of applications, particularly in their ester forms for the cosmetics, biomedical and food sectors. Actually, PGs are water soluble, biocompatible and highly functional materials. While short chain PGs are of interest for food and cosmetic industries, higher degrees of polymerization are of high interest in plastic industry because they induce an increase in the possibility of PGs further functionalization by increasing the numbers of available hydroxyl groups. The current industrial methods to produce PGs, such as basic hydrolysis of epichlorohydrin, have many disadvantages, such as toxic and carcinogenic starting materials, low selectivity, formation of high amounts of salts, etc. Using strong alkaline catalyst, such as $\mathrm{NaOH}$ and $\mathrm{KOH}$ as homogenous catalysts to directly convert glycerol to PGs, has also several disadvantages such as the difficulty to control the degree of polymerization; the impossibility to recover the homogeneous catalyst from the reaction medium after reaction and hence to reuse it; and the corrosion issues of the industrial equipment in presence of strong bases.

Hence, in the last two decades, attention has been paid to develop a heterogeneously-catalyzed process for glycerol direct polymerization over alkaline solid catalysts due to their advantages over alkaline homogeneous and acidic catalysts, such as a better control of the degree of polymerization, the ease of catalyst separation and recycling, as well as being non-corrosive for the industrial equipment. Based on the literature review, alkaline earth oxides such as $\mathrm{CaO}, \mathrm{BaO}$ and $\mathrm{SrO}$ are active catalysts for polyglycerols production and present a lower tendency to form acrolein (main by-products issued from glycerol double dehydration). For instance, $\mathrm{CaO}, \mathrm{SrO}$ and $\mathrm{BaO}$ have shown glycerol conversion close to $80 \%$ together with $90 \%$ selectivity to di- and triglycerol [5]. Ninety-six percent of glycerol conversion with $86 \%$ selectivity to di- and triglycerol were also reported in the presence of $\mathrm{Ca}_{1 \cdot 6} \mathrm{La}_{0 \cdot 4} \mathrm{Al}_{0 \cdot 6} \mathrm{O}_{3}$ [55]. Moreover, among alkaline earth oxides catalysts, $\mathrm{CaO}$-based catalysts such as $\mathrm{CaO}$, supported $\mathrm{CaO}$ on $\mathrm{CNF}$, dolomite (CaO-MgO mixed oxides), calcined eggshell and duck bones have shown high glycerol conversion with relatively high selectivity to PG2 and PG3 and nearly zero acrolein formation. However, these catalysts generally had a high selectivity to PG2 and PG3 and low selectivity to higher PGs, probably because of the low reaction temperature (Table 3). More importantly, they were 
unstable under polymerization reaction conditions mainly due to water formation during the reaction, which caused a partial dissolution of the catalyst and hence a homogenous contribution during glycerol polymerization reaction. This homogenous contribution has been reported by many groups in the forms of colloidal $\mathrm{Ca}(\mathrm{OH})_{2}$ and $\mathrm{Ca}^{2+}[3,5,6]$. For instance, Barros et al. [3] reported that $49 \%$ of solid $\mathrm{CaO}$-eggshell became homogeneous (i.e., dissolved in the reaction medium) after $24 \mathrm{~h}$ of reaction.

The proposed mechanism over $\mathrm{Ca}(\mathrm{OH})_{2}$ [40] also suggested an homogeneously catalyzed reaction by $\mathrm{Ca}$ ion species, which could explain the roles of leached species in the PGs reaction; the only mechanism proposed for heterogenous alkaline catalysts [5] involved Lewis acid sites, and cannot explain the highest activities of $\mathrm{BaO}$ and $\mathrm{SrO}$ with no acidic sites.

Besides the catalyst, the operational conditions such as temperature, pressure, atmosphere and reaction time can play a very important role on the glycerol conversion and the degree of polymerization of glycerol. For instance, Sangkhum et al. [60] reported that the glycerol conversion is doubled when the temperature is increased from 220 to $230^{\circ} \mathrm{C}$. Further, Kirby et al. [44] and Gholami et al. [55] also reported a full conversion of glycerol at $260^{\circ} \mathrm{C}$ and an increase the formation of higher polyglycerols (>PG3) and cyclic PGs. However, the effect of pressure and atmosphere has not been well studied in glycerol polymerization.

Thus, considering the high catalytic activity of $\mathrm{CaO}$ based catalysts and their wide availability, low cost and absence of toxicity in the case of catalyst leaching into the media, they could be viewed as promising for glycerol polymerization reactions. These alkaline catalysts could promote the polymerization of glycerol to shorter PGs, such as PG2 and PG3, at low temperature $\left(200-230^{\circ} \mathrm{C}\right)$ and induced the formation of higher degree of polymerization at higher temperatures $\left(>230^{\circ} \mathrm{C}\right)$. However, a key issue that has yet to be fully addressed is the effect of formed water in the system causing dissolution of the catalysts and homogeneous contribution in the glycerol polymerization reaction. Although the heterogeneously catalyzed reactions were performed in a Dean-Stark system to condense and collect water from the reaction mixture (Table 3), the formed water can still cause a partial dissolution of the catalysts. Researchers should therefore strive to design stable solid catalysts to polymerize glycerol and also investigate the homogenous contribution in the formation of PGs. Taking into account that the proposed mechanisms for PGs reaction are mostly for homogeneously catalyzed reactions $[8,12,40]$, distinguishing the influence of homogenous and heterogenous catalysts on polymerization of glycerol would also help understanding the "true" reaction mechanism, which is still matter of debates.

Author Contributions: N.E. wrote the paper; S.P., F.D. and B.K. led the study, revised the paper and gave advice on interpretation of references to complete the review and its conclusions. All authors have read and agreed to the published version of the manuscript.

Funding: Negissa Ebadipour's PhD grant was co-funded by Centrale Lille and Région Hauts-de-France.

Acknowledgments: Chevreul Institute (FR 2638), Ministère de l'Enseignement Supérieur, de la Recherche et de l'Innovation, Région Hauts-de-France and European Regional Development Fund (ERDF) are acknowledged for supporting this work. The authors would like to thank Joël Barrault for providing us some PGs samples.

Conflicts of Interest: The authors declare no conflict of interest.

\section{References}

1. Polyglycerol Market Size. Available online: https://www.grandviewresearch.com/industry-analysis/ polyglycerol-market (accessed on 5 May 2020).

2. Ciriminna, R.; Katryniok, B.; Paul, S.; Dumeignil, F.; Pagliaro, M. Glycerol-Derived Renewable Polyglycerols: A Class of Versatile Chemicals of Wide Potential Application. Org. Process Res. Dev. 2015, 19, 748-754. [CrossRef]

3. Barros, F.J.S.; Moreno-Tost, R.; Cecilia, J.A.; Ledesma-Muñoz, A.L.; de Oliveira, L.C.C.; Luna, F.M.T.; Vieira, R.S. Glycerol Oligomers Production by Etherification Using Calcined Eggshell as Catalyst. Mol. Catal. 2017, 433, 282-290. [CrossRef] 
4. García-Sancho, C.; Moreno-Tost, R.; Mérida-Robles, J.M.; Santamaría-González, J.; Jiménez-López, A.; Torres, P.M. Etherification of Glycerol to Polyglycerols over MgAl Mixed Oxides. Catal. Today 2011, 167, 84-90. [CrossRef]

5. Ruppert, A.M.; Meeldijk, J.D.; Kuipers, B.W.M.; Erné, B.H.; Weckhuysen, B.M. Glycerol Etherification over Highly Active CaO-Based Materials: New Mechanistic Aspects and Related Colloidal Particle Formation. Chem. Eur. J. 2008, 14, 2016-2024. [CrossRef] [PubMed]

6. Nieuwelink, A.-E. CaO/CNF for the Oligomerization of Glycerol. Master's Thesis, Department of Chemistry, Utrecht University, Utrecht, The Netherlands, 2015.

7. Barros, F.J.S.; Cecilia, J.A.; Moreno-Tost, R.; de Oliveira, M.F.; Rodríguez-Castellón, E.; Luna, F.M.T.; Vieira, R.S. Glycerol Oligomerization Using Low Cost Dolomite Catalyst. Waste Biomass Valorization 2018, 11, 1499-1512. [CrossRef]

8. Ionescu, M.; Petrović, Z.S. On the Mechanism of Base-Catalyzed Glycerol Polymerization and Copolymerization. Eur. J. Lipid Sci. Technol. 2018, 120, 1800004. [CrossRef]

9. Gholami, Z.; Abdullah, A.Z.; Lee, K.-T. Dealing with the Surplus of Glycerol Production from Biodiesel Industry through Catalytic Upgrading to Polyglycerols and Other Value-Added Products. Renew. Sustain. Energy Rev. 2014, 39, 327-341. [CrossRef]

10. Chong, C.C.; Aqsha, A.; Ayoub, M.; Sajid, M.; Abdullah, A.Z.; Yusup, S.; Abdullah, B. A Review over the Role of Catalysts for Selective Short-Chain Polyglycerol Production from Biodiesel Derived Waste Glycerol. Environ. Technol. Innov. 2020, 19, 100859. [CrossRef]

11. Jungermann, E.; Sonntag, N. (Eds.) Glycerine: A Key Cosmetic Ingredient; Cosmetic Science and Technology Series; Dekker: New York, NY, USA, 1991.

12. Martin, A.; Richter, M. Oligomerization of Glycerol-A Critical Review. Eur. J. Lipid Sci. Technol. 2010, 113, 100-117. [CrossRef]

13. Hejna, A.; Kosmela, P.; Formela, K.; Piszczyk, Ł.; Haponiuk, J.T. Potential Applications of Crude Glycerol in Polymer Technology-Current State and Perspectives. Renew. Sustain. Energy Rev. 2016, 66, 449-475. [CrossRef]

14. Cassel, S.; Debaig, C.; Benvegnu, T.; Chaimbault, P.; Lafosse, M.; Plusquellec, D.; Rollin, P. Original Synthesis of Linear, Branched and Cyclic Oligoglycerol Standards. Eur. J. Org. Chem. 2001, 2001, 875-896. [CrossRef]

15. Sunder, A.; Mülhaupt, R.; Frey, H. Hyperbranched Polyether-Polyols Based on Polyglycerol: Polarity Design by Block Copolymerization with Propylene Oxide. Macromolecules 2000, 33, 309-314. [CrossRef]

16. Kainthan, R.K.; Muliawan, E.B.; Hatzikiriakos, S.G.; Brooks, D.E. Synthesis, Characterization, and Viscoelastic Properties of High Molecular Weight Hyperbranched Polyglycerols. Macromolecules 2006, 39, 7708-7717. [CrossRef]

17. Nieberle, J. Hyperbranched Polyglycerols as Building Blocks for Complex Amphiphilic Structures: Synthesis, Characterization and Applications. Ph.D. Thesis, Johannes Gutenberg University, Mainz, Germany, 2008.

18. Kainthan, R.K.; Hester, S.R.; Levin, E.; Devine, D.V.; Brooks, D.E. In Vitro Biological Evaluation of High Molecular Weight Hyperbranched Polyglycerols. Biomaterials 2007, 28, 4581-4590. [CrossRef] [PubMed]

19. Pagliaro, M.; Rossi, M. The Future of Glycerol; RSC: Philadelphia, PA, USA, 2008. [CrossRef]

20. Babayan, V.K.; Lehman, H. Process for Preparation and Purification of Polyglycerols and Esters Thereof. U.S. Patent 3,637,774, 25 January 1972.

21. Lemke, D.W. Processes for Preparing Linear Polyglycerols and Polyglycerol Esters. U.S. Patent 6,620,904, 16 September 2003.

22. Hasenhuettl, G.L. Synthesis and Commercial Preparation of Food Emulsifiers. In Food Emulsifiers and Their Applications; Hasenhuettl, G.L., Hartel, R.W., Eds.; Springer: New York, NY, USA, 2008; pp. 11-37. [CrossRef]

23. Żołek-Tryznowska, Z.; Tryznowski, M.; Królikowska, J. Hyperbranched Polyglycerol as an Additive for Water-Based Printing Ink. J. Coat. Technol. Res. 2015, 12, 385-392. [CrossRef]

24. Meyer, J.; Friedrich, A.; Foetsch, H.; Springer, O.; von Hof, J.M.; Wenk, H.H. Polyglycerol Esters with a Particular Oligomer Distribution of the Polyglycerol. U.S. Patent 9,427,385, 30 August 2016.

25. Thomas, A.; Müller, S.S.; Frey, H. Beyond Poly(Ethylene Glycol): Linear Polyglycerol as a Multifunctional Polyether for Biomedical and Pharmaceutical Applications. Biomacromolecules 2014, 15, 1935-1954. [CrossRef]

26. Daly, S.; Maitra, P.; Setiawan, B. Sunscreen Compositions Containing a Uv-Absorbing Polyglycerol and a Non-Uv-Absorbing Polyglycerol. U.S. Patent 14/674,536, 12 November 2015. 
27. Zhang, H.; Grinstaff, M.W. Recent Advances in Glycerol Polymers: Chemistry and Biomedical Applications. Macromol. Rapid Commun. 2014, 35, 1906-1924. [CrossRef]

28. Ayoub, M.; Khayoon, M.S.; Abdullah, A.Z. Synthesis of Oxygenated Fuel Additives via the Solventless Etherification of Glycerol. Bioresour. Technol. 2012, 112, 308-312. [CrossRef]

29. Morlino, N.M.; Sweeny, P.G.; Curham, B.D. Polyglycerol Antifoam Agents in Paper Processing. U.S. Patent 5,429,718, 4 July 1995.

30. Nilewski, M.; Favresse, P.; Scharf, A.; Gehrmann, P.; Mettin, T.; Schwan, M.; Springer, O.; Wied, T. Use of Polyglycerol Partial Esters as Defoamers. U.S. Patent 9,738,797, 22 August 2017.

31. Lu, Y. 10-20 Polyglycerol and Production Method Thereof. Patent CN104650340A, 27 May 2015.

32. Pinto, B.P.; De Araujo Mota, C.J. Developments in Glycerol Byproduct-Based Biorefineries. In Advances in Biorefineries; Woodhead Publishing: Cambridge, UK, 2014; pp. 364-385. [CrossRef]

33. Milewski, A.; Dydo, P.; Jakóbik-Kolon, A.; Czechowicz, D.; Babilas, D.; Burek, M.; Waśkiewicz, S.; Byczek-Wyrostek, A.; Krawczyk, T.; Kasprzycka, A. Preparation of Triglycerol from Glycerol and Epichlorohydrin at Room Temperature: Synthesis Optimization and Toxicity Studies. ACS Sustain. Chem. Eng. 2018, 6, 13208-13216. [CrossRef]

34. Endo, T.; Omori, H. Process for Producing Polyglycerol. Patent EP1568677B1, 8 January 2014.

35. Cespi, D.; Cucciniello, R.; Ricciardi, M.; Capacchione, C.; Vassura, I.; Passarini, F.; Proto, A. A Simplified Early Stage Assessment of Process Intensification: Glycidol as a Value-Added Product from Epichlorohydrin Industry Wastes. Green Chem. 2016, 18, 4559-4570. [CrossRef]

36. Mukbaniani, O.V.; Abadie, M.J.M.; Tatrishvili, T.N. (Eds.) Chemical Engineering of Polymers: Production of Functional and Flexible Materials, 1st ed.; Apple Academic Press: Palm Bay, FL, USA, 2017. [CrossRef]

37. Lemke, D.W.; Nivens, S. Process for Prepapring Polycerol and Mixed Ethers. U.S. Patent 12/221,608, 11 December 2008.

38. Plasman, V.; Caulier, T.; Boulos, N. Polyglycerol Esters Demonstrate Superior Antifogging Properties for Films. Plast. Addit. Compd. 2005, 7, 30-33. [CrossRef]

39. Sayoud, N.; De Oliveira Vigier, K.; Cucu, T.; De Meulenaer, B.; Fan, Z.; Lai, J.; Clacens, J.-M.; Liebens, A.; Jérôme, F. Homogeneously-Acid Catalyzed Oligomerization of Glycerol. Green Chem. 2015, 17, 4307-4314. [CrossRef]

40. Salehpour, S.; Dubé, M.A. Towards the Sustainable Production of Higher-Molecular-Weight Polyglycerol. Macromol. Chem. Phys. 2011, 212, 1284-1293. [CrossRef]

41. Medeiros, M.A.; Araujo, M.H.; Augusti, R.; de Oliveira, L.C.A.; Lago, R.M. Acid-Catalyzed Oligomerization of Glycerol Investigated by Electrospray Ionization Mass Spectrometry. J. Braz. Chem. Soc. 2009, 20, 1667-1673. [CrossRef]

42. Krisnandi, Y.K.; Eckelt, R.; Schneider, M.; Martin, A.; Richter, M. Glycerol Upgrading over Zeolites by Batch-Reactor Liquid-Phase Oligomerization: Heterogeneous versus Homogeneous Reaction. ChemSusChem 2008, 1, 835-844. [CrossRef]

43. Harris, E.G.; Hees, U.; Bunte, R.; Hachgenei, J.W.; Kuhm, P. Process for the Production of Oligoglycerol Mixtures of Increased Diglycerol Content. U.S. Patent 5,349,094, 20 September 1994.

44. Kirby, F.; Nieuwelink, A.-E.; Kuipers, B.W.M.; Kaiser, A.; Bruijnincx, P.C.A.; Weckhuysen, B.M. CaO as Drop-In Colloidal Catalysts for the Synthesis of Higher Polyglycerols. Chem. Eur. J. 2015, 21, 5101-5109. [CrossRef]

45. Richter, M.; Krisnandi, Y.; Eckelt, R.; Martin, A. Homogeneously Catalyzed Batch Reactor Glycerol Etherification by CsHCO3. Catal. Commun. 2008, 9, 2112-2116. [CrossRef]

46. Garti, N.; Aserin, A.; Zaidman, B. Polyglycerol Esters: Optimization and Techno-Economic Evaluation. J. Am. Oil Chem. Soc. 1981, 58, 878-883. [CrossRef]

47. Clacens, J.-M.; Pouilloux, Y.; Barrault, J. Selective Etherification of Glycerol to Polyglycerols over Impregnated Basic MCM-41 Type Mesoporous Catalysts. Appl. Catal. Gen. 2002, 227, 181-190. [CrossRef]

48. Harris, B. Polyglycerol Esters of Aliphatic Acids of Relatively High Molecular Weight. U.S. Patent 2,023,388, 3 December 1935.

49. Charles, G.; Clacens, J.-M.; Pouilloux, Y.; Barrault, J. Préparation de Diglycérol et Triglycérol Par Polymérisation Directe Du Glycérol En Présence de Catalyseurs Mésoporeux Basiques. Ol. Corps Gras Lipides 2003, 10, 74-82. [CrossRef] 
50. Nosal, H.; Nowicki, J.; Warzała, M.; Nowakowska-Bogdan, E.; Zarębska, M. Synthesis and Characterization of Alkyd Resins Based on Camelina Sativa Oil and Polyglycerol. Prog. Org. Coat. 2015, 86, 59-70. [CrossRef]

51. Ayoub, M.; Sufian, S.; Hailegiorgis, S.M.; Ullah, S.; Uemura, Y. Conversion of Glycerol to Polyglycerol over Waste Duck-Bones as a Catalyst in Solvent Free Etherification Process. IOP Conf. Ser. Mater. Sci. Eng. 2017, 226, 012073. [CrossRef]

52. Chen, X.; Peng, M. Method for Preparing Polyglycerine with High Degree of Polymerization. Patent CN102532515A, 4 July 2012.

53. Sivaiah, M.V.; Robles-Manuel, S.; Valange, S.; Barrault, J. Recent Developments in Acid and Base-Catalyzed Etherification of Glycerol to Polyglycerols. Catal. Today 2012, 198, 305-313. [CrossRef]

54. Ayoub, M.; Abdullah, A.Z.; Ahmad, M.; Sultana, S. Performance of Lithium Modified Zeolite Y Catalyst in Solvent-Free Conversion of Glycerol to Polyglycerols. J. Taibah Univ. Sci. 2014, 8, 231-235. [CrossRef]

55. Gholami, Z.; Abdullah, A.Z.; Lee, K.-T. Selective Etherification of Glycerol over Heterogeneous Mixed Oxide Catalyst: Optimization of Reaction Parameters. Chem. Eng. Sci. 2013, 1, 79-86. [CrossRef]

56. Gholami, Z.; Abdullah, A.Z.; Lee, K.-T. Glycerol Etherification to Polyglycerols Using Ca1+xAl1-xLaxO3 Composite Catalysts in a Solventless Medium. J. Taiwan Inst. Chem. Eng. 2013, 44, 117-122. [CrossRef]

57. Gholami, Z.; Abdullah, A.Z.; Lee, K.T. Heterogeneously Catalyzed Etherification of Glycerol to Diglycerol over Calcium-Lanthanum Oxide Supported on MCM-41: A Heterogeneous Basic Catalyst. Appl. Catal. Gen. 2014, 479, 76-86. [CrossRef]

58. Guerrero-Urbaneja, P.; García-Sancho, C.; Moreno-Tost, R.; Mérida-Robles, J.; Santamaría-González, J.; Jiménez-López, A.; Maireles-Torres, P. Glycerol Valorization by Etherification to Polyglycerols by Using Metal Oxides Derived from MgFe Hydrotalcites. Appl. Catal. Gen. 2014, 470, 199-207. [CrossRef]

59. Pérez-Barrado, E.; Pujol, M.C.; Aguiló, M.; Llorca, J.; Cesteros, Y.; Díaz, F.; Pallarès, J.; Marsal, L.F.; Salagre, P. Influence of Acid-Base Properties of Calcined MgAl and CaAl Layered Double Hydroxides on the Catalytic Glycerol Etherification to Short-Chain Polyglycerols. Chem. Eng. J. 2015, 264, 547-556. [CrossRef]

60. Sangkhum, P.; Yanamphorn, J.; Wangriya, A.; Ngamcharussrivichai, C. Ca-Mg-Al Ternary Mixed Oxides Derived from Layered Double Hydroxide for Selective Etherification of Glycerol to Short-Chain Polyglycerols. Appl. Clay Sci. 2019, 173, 79-87. [CrossRef]

61. Kaiser, A.; Weckhuysen, B.M.; Leinweber, D.; Kirby, F.; Scherl, F.X.; Metz, H.J.; Bruijnincx, P.C.A. Preparation of Polyglycerols. Patent WO2015122770A1, 20 August 2015.

62. Han, Y.H.; Kim, H.R.; Han, I.S.; Choi, H.O.; Kim, H.S.; An, S.Y.; Youn, Y.H. Metal Oxide Catalysts for Etherification, Method for Its Preparation Thereof, and Method for the Production of Linear Polyglycerol Using the Same. Patent WO2010044531A2, 22 April 2010.

63. Barrault, J.; Clacens, J.-M.; Pouilloux, Y. Methods for Etherifying Glycerol, and Catalysts for Implementing Said Methods. Patent WO2001098243A1, 27 December 2001.

64. Barriau, E. Hyperbranched Polyether Polyols as Building Blocks for Complex Macromolecular Architectures. Ph.D. Thesis, Johannes Gutenberg University, Mainz, Germany, 2005.

65. Cammenga, H.K.; Schulze, F.W.; Theuerl, W. Vapor Pressure and Evaporation Coefficient of Glycerol. J. Chem. Eng. Data 1977, 22, 131-134. [CrossRef]

66. Wilson, R.; van Schie, B.J.; Howes, D. Overview of the Preparation, Use and Biological Studies on Polyglycerol Polyricinoleate (PGPR). Food Chem. Toxicol. 1998, 36, 711-718. [CrossRef]

67. Nalawade, S.P.; Picchioni, F.; Janssen, L.P.B.M. Supercritical Carbon Dioxide as a Green Solvent for Processing Polymer Melts: Processing Aspects and Applications. Prog. Polym. Sci. 2006, 31, 19-43. [CrossRef]

68. de Caro, P.; Bandres, M.; Urrutigoïty, M.; Cecutti, C.; Thiebaud-Roux, S. Recent Progress in Synthesis of Glycerol Carbonate and Evaluation of Its Plasticizing Properties. Front. Chem. 2019, 7. [CrossRef] [PubMed]

(C) 2020 by the authors. Licensee MDPI, Basel, Switzerland. This article is an open access article distributed under the terms and conditions of the Creative Commons Attribution (CC BY) license (http://creativecommons.org/licenses/by/4.0/). 